\section{Michigan Technological

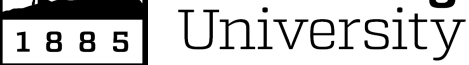

Michigan Technological University Digital Commons @ Michigan Tech

\title{
Incorporating Shading Losses in Solar Photovoltaic Potential Assessment at the Municipal Scale
}

Ha T. Nguyen

Boston University

Joshua M. Pearce

Michigan Technological University

Follow this and additional works at: https://digitalcommons.mtu.edu/materials_fp

\section{Recommended Citation}

Ha T. Nguyen and Joshua M. Pearce, "Incorporating Shading Losses in Solar Photovoltaic Potential Assessment at the Municipal Scale" Solar Energy 86(5), pp. 1245-1260 (2012).

http://digitalcommons.mtu.edu/materials_fp/38 
Published as: Ha T. Nguyen and Joshua M. Pearce, "Incorporating Shading Losses in Solar Photovoltaic Potential Assessment at the Municipal Scale” Solar Energy 86(5), pp. 1245-1260 (2012). DOI: http://dx.doi.org/10.1016/j.solener.2012.01.017

\title{
Incorporating Shading Losses in Solar Photovoltaic Potential Assessment at the Municipal Scale
}

Ha T. Nguyen ${ }^{1}$ and Joshua M. Pearce ${ }^{2 *}$

${ }^{1}$ Department of Geography and Environment

Boston University, Boston, Massachusetts 02215, USA

${ }^{2}$ Department of Materials Science \& Engineering

Department of Electrical \& Computer Engineering

Michigan Technological University Houghton, MI 49931, USA

\author{
*Corresponding author: \\ 601 M\&M Building \\ 1400 Townsend Drive \\ Houghton, MI 49931-1295 \\ ph: $1-906-487-1466$ \\ fax:1-906-487-2934 Fax \\ pearce@mtu.edu
}

\begin{abstract}
Recently several algorithms have been developed to calculate the solar photovoltaic (PV) potential on the basis of 2.5D raster data that can capture urban morphology. This study provides a new algorithm that (i) incorporates both terrain and near surface shadowing effects on the beam component; (ii) scales down the diffuse components of global irradiation; and (iii) utilizes free and open source GRASS and the module r.sun in modeling irradiation. This algorithm is semiautomatic and easy to upgrade or correct (no hand drawn areas), open source, detailed and provides rules of thumb for PV system design at the municipal level. The workflow is pilot tested on LiDAR data for 100 buildings in downtown Kingston, Ontario. Shading behavior was considered and suitable roof sections for solar PV installations selected using a multi-criteria objective. At sub-meter resolution and small time steps the effect of occlusion from near object was determined. Annual daily horizontal irradiation values were refined at $0.55 \mathrm{~m}$ resolution and were shown to be lower than those obtained at $90 \mathrm{~m}$ by $30 \%$. The robustness of r.sun as capable of working with different levels of surface complexity has been confirmed. Finally, the trade off of each computation option (spatial resolution, time step and shading effect) has been quantified at the meso scale, to assist planners in developing the appropriate computation protocols for their regions.
\end{abstract}

Keywords: GIS; Photovoltaic; Renewable energy; Solar energy; Solar irradiation modeling ; Shading

\author{
Abbreviations \\ $\left(A_{p v}\right)^{\text {site }}$ : the true area of the roof sections selected as suitable for installing PV \\ $\left(A_{\text {roof }}\right)^{\text {site }}$ : the true area of all the roofs considered in the simulation \\ $\left(A_{\text {projroof }}\right)^{\text {site }}$ : the projected area of all the roofs considered in the simulation \\ DSM: Digital Surface Model \\ DTM: Digital Terrain Model \\ GIS : Geographic Information System \\ GRASS : Geographic Resources Analysis Support System \\ GW : GigaWatts $\left(10^{9} \mathrm{~W}\right)$ \\ $\mathrm{I}_{\mathrm{b}}$ : beam irradiation \\ $\mathrm{I}_{\text {diff }}:$ diffuse irradiation \\ $\mathrm{I}_{\mathrm{gb}}$ : Global horizontal irradiation (GHI) \\ $\mathrm{I}_{\mathrm{L} / \mathrm{P}}$ : irradiation loss per plane \\ LiDAR: Light Detection And Ranging technology \\ m: meter \\ r.horizon : Horizon angle computation from a DEM in GRASS \\ r.sun : a solar irradiance and irradiation model for GRASS \\ $\mathrm{S}$ : shading \\ SAGA: System for Automated Geoscientific Analyses \\ SVF : Sky View Factor \\ SOLPOS : Solar position and intensity calculator \\ $\beta$ : slope
}


Published as: Ha T. Nguyen and Joshua M. Pearce, "Incorporating Shading Losses in Solar Photovoltaic Potential Assessment at the Municipal Scale” Solar Energy 86(5), pp. 1245-1260 (2012). DOI: http://dx.doi.org/10.1016/j.solener.2012.01.017

$\gamma$ : surface azimuth

$\delta$ : solar declination

$\theta_{\mathrm{s}}$ : solar altitude

$\mathrm{\kappa}$ : clear sky index

$\omega$ : solar hour angle

$\phi$ : latitude

2.5D : 2 dimensional graphical projections that to appear to be three-dimensional (3D)

\section{Introduction}

Solar photovoltaic (PV) energy conversion offers a sustainable method of producing electricity to provide for contemporary society's needs (Pearce, 2002). The advantages of PV in producing electricity are: i) generating no atmospheric emissions or radioactive waste during use, ii) acting as a distributed electrical generation source, iii) assisting in national energy security (Olz et al., 2007; Wong, 2009) and iv) improving long-term economic growth (Branker and Pearce, 2010; Myrans 2009; Fthenakis et al., 2008) for any country that aggressively develops the technology. This has led to international cooperation and technology investment over the past 25 years, which in turn has given rise to substantial gains in solar PV cell performance (d’Estaintot, 2000; European Photovoltaic Industry Association, 2003; Hoffman, 2006; Green et al., 2010). Solar cells made from a variety of materials have demonstrated efficiencies over ten percent and are currently manufactured globally. As the technological proficiency of the solar cell industry matured, the total shipments of solar cells increased rapidly. In the last decade (to 2010), global solar PV deployment has increased from $<1 \mathrm{GW}$ to $>16 \mathrm{GW}$ with an annual growth rate of more than 40\% (Mints, 2011; IEA, 2010; REN21, 2010; Doty et al., 2010; Price \& Margolis, 2010). Although this growth rate is impressive, it must be kept in context of the global energy market. The 2000 peak electrical generation capacity in the U.S. was 825 GigaWatts $\left(\mathrm{GW}=10^{9} \mathrm{~W}\right)$, while the cumulative total global installed solar PV was less than a single GW. Within the first half of the $21^{\text {st }}$ century de Vries et al. (2006) predicted that the technical potential for solar PV will grow by 4 times to reach 4,195 PWh/ year by 2050.

Recent discussion on a 'new logic of infrastructure provision' (Marvin and Guy, 1997), a 'paradigm shift in energy policy’ (Helm, 2005), and the use of 'dynamic carbon life-cycle analysis’ (Kenny, et al., 2010) to guide energy choices has mentioned the contribution of the increasing technological competitiveness of solar PV, among other kinds of renewable energy sources. However, in the debates on urban and regional development and regional infrastructure policy, the delivery of utility services still seems to be taken for granted and to be left to engineers, network operators and (supra-)national utility regulators. Consequently, there has been little research on the urban and regional impacts of utility restructuring and the changing environment for urban and regional governance (Marvin et al., 1999; Monstad, 2007) with a large scale introduction of PV. To take advantage of continued price declines observed in PV technology and to create extra opportunities for the price declines on a geographical context, an understanding the urban local potential (roof space and solar exposure) and an ability to simulate solar availability given the local (urban) topology are critical for utility planning, accommodating grid capacity, deploying financing schemes and formulating future adaptive policies (Wiginton et al., 2010).

The single problem of solar radiation simulation makes clear the necessity for a multidisciplinary and systemic approach related to specialties as different as meteorology, geography, architecture and urban systems engineering. The goal of several existing projects and recent workshops (SEUS $2010^{1}$, IEA PVPS Task $10^{2}$, POLIS ${ }^{3}$ ) has been to examine this issue as a whole, from the climatic data to the urban development strategies, showing how the new tools (second generation satellites, very large geometric models and technological improvement in the data acquisition) can be integrated to obtain better quantification and control in order to transmit the useful information between the actors at macro (territory), meso (city) and micro (building) scales (SEUS, 2010). The sheer numbers of existing packages ${ }^{4}$ (e.g. Radiance 1992, Heliodon2, SunTools, etc.) and generations of projects (EU PVP Task 102007 - 2010, POLIS 2009 2012 ) confirm the promise and excitement that the topic offers.

Despite (i) the ongoing interests from the public, the government and different sectors in the scientific community (architecture, meteorology, geography, engineering); (ii) the previous and existing investigations; and (iii) the

1 http://www.utc.fr/seus/

2 http://iea-pvps-task10.org/

3 http://www.polis-solar.eu/solar-urban-planning-in-polis/

4 http://www.urbanclimate.net/E_2TOOLS.HTM 
Published as: Ha T. Nguyen and Joshua M. Pearce, "Incorporating Shading Losses in Solar Photovoltaic Potential Assessment at the Municipal Scale” Solar Energy 86(5), pp. 1245-1260 (2012). DOI: http://dx.doi.org/10.1016/j.solener.2012.01.017

emergence of new tools (Carneiro et al, 2009; SEUS 2010) a comprehensive and reliable toolkit for sustainable urban design is lacking among practitioners. Very few applications have been implemented to process the data for the environmental analysis and to get quick, but reasonably accurate insight into the performance of the urban morphology. Much less takes place in order to streamline the communication across different disciplines of interest and hence a perceived difficulty when one desires to do a solar photovoltaic assessment on the meso and micro scale (Wiginton et al., 2010; Nguyen \& Pearce, 2011; Nguyen et al., 2011, forthcoming).

Considered individually site data acquisition and derivation (i.e. urban texture reconstruction and modeling) and spectral and meteorological performance of the urban fabric are attractive and proliferate research areas ${ }^{5}$. However the algorithms introduced are (i) for macro scale or for micro scale - missing the urban district in the middle (Jochem et al., 2009; Carneiro et al., 2009); (ii) site specific (Kassner et al., 2008; Barsenic et al., 2008); (iii) of strict requirements pertaining the data quality and involved expertise (Wiginton et al., 2010; Kurochi et al., 2007; Levinson et al., 2009) or (iv) vague and hence impossible to adapt elsewhere. Scaling site assessment has been one of the larger barriers and is currently accomplished manually at high cost (i.e. time and expense) or via crude drawing on Google Earth visualizations. None of the current practices is scalable when both high quality and low cost is considered at the GigaWatt (GW) scale. This paper responds to the need for streamlined communication between sectors (remote sensing and solar energy engineering) and scales (macro/ meso/ micro) by coupling large scale solar irradiation simulations with site data acquired with Light Detection And Ranging technology (LiDAR) to identify individual roof facades suitable for PV applications and calculate the shading losses these arrays would experience as one single electricity district unit.

\section{Background}

Three factors that determine the interaction of the solar radiation with the earth's atmosphere and surface are (i) the sun - earth geometry: the earth's rotation and revolution around the sun determines the available extraterrestrial radiation on solar position above horizon; (ii) the topography of the terrain: slope, aspect, shadowing effects of the neighboring terrain features and (iii) the attenuation of solar energy by the atmosphere (i.e. by aerosols and clouds) (Suri \& Hofierka, 2004; Remund et al., 2003). Accordingly a successful and accurate simulation is conditional upon (i) the determination of the solar vector; (ii) the input of local terrain or a Digital Surface Model (DSM, which in this case, is reconstructed from LiDAR data); and (iii) the choice of an irradiation/ shading model, which may have its own required parameters (e.g. the Linke turbidity (Remund et al., 2003) and clear sky index).

\subsection{Calculations of the solar vector}

For the purpose of this study, which focuses on horizontal irradiation on roof tops, an algorithm that has a maximum error between 0.01 and 0.008 , limited time window but fast and effortless computation is deemed sufficient. Hence the SOLPOS calculator was chosen. It is valid between 1950 and 2050 with an uncertainty of 0.01 degrees. $^{6}$

\subsection{Large scale solar irradiation simulations}

An overview of the available solar irradiation datasets and simulation projects is given by Nguyen \& Pearce (2010). Essential background of irradiation models is covered in Duffie \& Beckman (2001).

\subsection{Shading algorithms}

Budin \& Budin (1982) gives a detailed and mathematically rigorous account of the shading algorithm, which begins with fixing a coordinate system at the point of interest on the earth's surface and then describing the sun's position through the use of the hour angle $\omega$, site latitude $\phi$ and solar declination $\delta$. In that way, the relationship of the expression of the sun's position in a spherical coordinate system of the local tilted plane undergoing through two transformations: (i) transformation from the spherical coordinate system of the local tilted plane to that of the horizontal plane; and (ii) transformation from the spherical coordinate system of the horizontal plane to that of the equator.

Shading calculations were traced back to the consideration of the shadow of an isolated point on the plane surface with an arbitrary orientation. Essentially given site latitude $\phi$, declination $\delta$, surface azimuth $\gamma$, slope $\beta$ and solar hour angle $\omega$ for any day, the shadow's position of a particular site at a particular time of hour and day can computed as a function of solar altitude $\theta_{s}$ and solar azimuth $\gamma_{s}$. From the perspective of a solar PV engineer, this is helpful for site

5 http://www.urbanclimate.net/E_2TOOLS.HTM

6 http://www.nrel.gov/midc/solpos/ 
Published as: Ha T. Nguyen and Joshua M. Pearce, "Incorporating Shading Losses in Solar Photovoltaic Potential Assessment at the Municipal Scale” Solar Energy 86(5), pp. 1245-1260 (2012). DOI: http://dx.doi.org/10.1016/j.solener.2012.01.017

inspection. However such shading diagrams can only be used for a pre-determined location, the latitude $\phi$, declination $\delta$, surface azimuth $\gamma$ and slope $\beta$ of which have been pre-determined. Hence the method can not be applied to site selection.

On a more universal and theoretical level Horn (1981) narrated the evolution of automatic hill shading techniques against the basics of representations of the relief forms in painting, mathematics, physics and the emergence of DTMs and the reflectance map. To create a reflectance map is to capture the dependence of the scene brightness on the surface orientation, i.e. the local gradient. The components of the gradient are the slopes or the changing of elevation in the west-to-east direction and in the south to north direction. The better way to estimate these slopes is by using a weighted average of three such central differences over a 3x3 neighborhood centered by the pixel of interest (Horn 1981). Horn (1981) then proceeded to discuss relief shading methods in the following groups:

- rotationally symmetric reflectance maps-gray tone depends on slope only

- methods based on varying line spacing or thickness to modulate average reflectance

- ideal diffuse reflectance and various approximations

- gray tone depends only on the slope of the surface in the direction away from the assumed light source

- methods depending on more elaborate niodels of diffuse reflectance from porous material, such as that covering the lunar surface

- models for gloss and lustrous reflection-smooth surface, extended source and rough surface, point source.

The relief technique adopted by shading commands in GIS packages belongs to the third group. The apparent brightness of a surface element depends on its orientation with respect to the viewer and the light source. Further the amount of light captured by a surface patch will depend on its inclination relative to the incident beam. It is commonly assumed that the radiance (apparent brightness) of the surface patch is also proportional to $\cos \theta$ although this is generally not the case since light may be reflected differently in different directions, as can be seen by considering a specularly reflecting material. One can however assume an ideal surface that reflects all light incident on it and appears equally bright from all viewing directions. Such a surface is called an ideal diffuser or Lambertian reflector and has the property that its radiance equals the irradiation divided by $\pi$. In this special case the radiance is proportional to the cosine of the incident angle. Thus the amount of shading, $\mathrm{S}$, is given as:

$$
S=255 * \cos \theta_{z} * \cos \beta+\sin \theta_{z} * \sin \beta * \cos \left(\gamma_{s}-\gamma\right)
$$

where 255 is the maximum gradient for a 16-bit color system. The cartographic practice to assume a light source in the northwest at a $45^{\circ}$ elevation above the horizon has made its way into the default of shading algorithms in GIS packages, which can be overwritten by manually entering values for solar altitude and azimuth at specified time and location output from the SOLPOS calculator.

The background above suffices to elucidate the basis behind Hillshade ${ }^{7}$ function which was used by Levinson et al. (2009) and which was found to be interchangeable with the open source r.sunmask ${ }^{8}$.

\subsection{Site data derivation from LiDAR}

A previous work (Nguyen et al., 2011) gave a thorough examination of the background, challenges and existing approaches to extract urban texture information from remote sensing data, especially via airborne laser scanning and went on to present a methodology to extract, segment and reconstruct roof planes from a given LiDAR point cloud. The methodology was used to create the site for simulation in this study (section 3.1).

\subsection{Sky view factor $(S V F)^{9}$}

Carneiro et al. (2009) used SVF to scale down the amount of diffuse irradiation received by a roof and SVF is calculated from the viewpoint of the roof of interest. By the definition proposed by Souza et al. (2003), SVF is the relationship between the visible area of the sky and the portion of the sky covered by surrounding buildings and other obstacles viewed from a specific point of observation. This coincides with the use of view factor in an isotropic sky

7 http://webhelp.esri.com/arcgiSDEsktop/9.3/index.cfm?TopicName=Producing_a_hillshade 8 http://www.phygeo.uni-hannover.de/grass/grass70/manuals/html70_user/r.sunmask.html

9 The ratio of the radiation received (or emitted) by a planar surface to the radiation emitted (or received) by the entire hemispheric environment is called the sky view factor (SVF). 
Published as: Ha T. Nguyen and Joshua M. Pearce, "Incorporating Shading Losses in Solar Photovoltaic Potential Assessment at the Municipal Scale” Solar Energy 86(5), pp. 1245-1260 (2012). DOI: http://dx.doi.org/10.1016/j.solener.2012.01.017

model (Duffie \& Beckman, 2001). By inputing a Digital Surface Model (DSM) an increased urban complexity is integrated with the sky view factor estimation.

Although a first reading of approaches towards SVF calculations can create an impression that SVF analysis is similar to Viewshed or visibility computation, they are not the same because the latter uses the elevation value of each cell of the ground data to determine visibility to, or from a particular cell. Viewshed tools allow the user to determine the visibility on a surface from point to point along a given line of sight or across the entire surface in a viewshed. This method of determining visibility from a cell location is useful for certain applications involving questions of visibility from other surface points, but it does not compute visible locations that are off the surface such as objects in space as in the case of SVF calculation (Yousef, 2010). Further the visibility computation can be avoided when the objective is limited to evaluation of SVF since in this situation it suffices to count the number of the non-cover proxels on the sky vault. An open source version of the Sky View Factor Extension has been available as a module inside the System for Automated Geoscientific Analyses (SAGA 2.0). ${ }^{10}$ The accuracy of the SVF is determined by the angular resolution and the radius of the hemisphere considered in the sky view (Gal et al., 2009). The use of 5 - $10^{\circ}$ in both altitude and azimuth directions and $20-30 \mathrm{~m}$ in radius of the sky dome are conventionally used (Gal et al., 2009; Yousef 2010).

\section{Methodology \\ 3.1 The choice of site}

The selected site shown in Figure 1 is of comparable size/resolution with previous studies (Kassner et al., 2009; Carneiro et al., 2009, Bersenic et al., 2008, Kurochi et al., 2007, Nguyen \& Pearce 2011); and has over 60 buildings to support the confidence of the novel building extraction accuracy assessment (Nguyen et al. 2011, forthcoming). The site shown in Figure 1 covers about 100 buildings of high point density and from a mixture of sectoral (residential and commercial) and structural variations (flat/ garbled/ pitched). There are not many trees, albeit tall trees to render the tree canopy reconstruction a necessary component in the simulation. The DSM input into r.sun is also shown in Figure 1.

\section{\{Insert Fig.1\}}

The DSM is the product of the process described in Figures 2a-c below. In this study ArcGIS9.3 was used for the steps in Figure 2 a,b,c, Matlab in Figure 2b and in Figue 2c the irradiance modeling was done in GRASS. To perform all of the steps in open source software Scilab can be used in replacement of Matlab and GRASS for ArcGIS. First, the altimetry of the last LiDAR return pulses were used for building detection and extraction. The latter was carried out in hybrid with the footprint shapefile. The data noise was reduced by using a buffer zone and an elevation floor limit. These steps are summarized in Figure 2a. The remaining error-free data was fit into different planar faces, the procedure of which is explained in Figure 2b. Figure 2c shows how the working geometry is transformed from points to grid via Delaunay triangulation. ${ }^{11}$ Accordingly, the resultant area was next converted to raster at a resolution of $0.55 \mathrm{~m}$ and added on top of the existing DTM to create the DSM. It should be pointed out that it is essential that in the mosaic to create a new raster command, the same bit (32 or 16) and data type (floating or continuous) with the DTM is specified.

\{Insert Fig. 2a,b,c

\section{2 r.sun}

The use of r.sun on large scale solar photovoltaic assessments was demonstrated by Nguyen and Pearce (2010). The script details, with embedded SOLPOS calculator and an option to speed up the simulation time on large grids (via r.horizon) are described by Neteler \& Mitasova (2008). The package is sophisticated and flexible enough to handle the dynamics of solar radiation and the complexity of urban areas (Hofierka \& Kanuk, 2009).

\subsection{Insolation}

Global horizontal irradiation $(\mathrm{GHI})$ or $\mathrm{I}_{\mathrm{gb}}$ is defined as:

10 http://www.saga-gis.org/en/index.html

11 Delaunay triangulations maximize the minimum angle of all the angles of the triangles in the triangulation and tend to avoid skinny triangles by ensuring that no point in a set of points is inside the circumcircle of any triangle considered. (B. Delaunay: Sur la sphère vide, Izvestia Akademii Nauk SSSR, Otdelenie Matematicheskikh i Estestvennykh Nauk, 7:793-800, 1934). 
Published as: Ha T. Nguyen and Joshua M. Pearce, "Incorporating Shading Losses in Solar Photovoltaic Potential Assessment at the Municipal Scale” Solar Energy 86(5), pp. 1245-1260 (2012). DOI: http://dx.doi.org/10.1016/j.solener.2012.01.017

$$
I_{g b}=I_{b}+I_{d i f f} * s v f
$$

where $I_{g b}, I_{b}$ (beam), shade and $I_{\text {diff }}$ (diffuse) are all rasters (Wahschning \& Hanitsch, 1995; Duffie \& Beckman, 2001; Hantzschel et al., 2005; Jochem et al., 2009; Carneiro et al., 2009; Merino et al., 2010), the values of which can be output hourly by the script r.sun. The raster svf, on the other hand, contains time independent values.

Only GHI was generated, meaning that the PV output given here will be for panels laid on the same angles as their respective roof ( 0 degrees if flat and otherwise for tilted roofs). This simplified the calculation because the cloud effect included in the clear sky index, $\kappa$, is given by

$$
\kappa=\frac{\left(I_{g b}\right)^{\text {overcast }}}{\left(I_{g b}\right)^{\text {clear }}}
$$

This is the convenience of inputting a DSM to the simulation script. The clear sky index also includes the shadowing effect of the surrounding terrain (Jochem et al., 2009). As the surface input is a DSM, the terrain in question also includes surrounding buildings, trees and other obstacles. The use of a DSM to capture urban morphology has been confirmed by Ratti et al. (2005) and sets this work apart from Jochem et al. (2009) since it can incorporate both terrain and near surface shadowing effect as seen below in section 4 .

\subsection{Shading behavior}

If a PV panel is optimized for the summer, this optimal performance will dominate the annual output (Duffie \& Beckman, 2001). It follows that any loss in the summer will significantly downgrade the suitability of any roof section for PV, hence by running shading every hour between the sunset and sunrise for the mean monthly days of the summer (May - August) sufficient understanding on the shading occurring on the roof can be developed. To prove this hypothesis, two sets of simulations were carried out. In the first set, hourly irradiation was computed for the months of May through August without shading and again with shading. In the second set, irradiation at 3 minute time steps was computed for all twelve months without shading and again with shading. The goal is to determine whether simulating only the summer irradiation loss by shading one can approximate the annual average summer irradiation. If this is the case, significant amounts of time and effort can be saved for future simulations of other geographic regions.

Within r.sun there are two ways to incorporate shading into insolation modeling: either by checking the option '-s', which is equivalent to choosing Hillshade in ArcGIS, ${ }^{12}$ or by combining r.sun with r.horizon. The latter is available for GRASS version 6.4.0 onwards and is interchangeable with the former approach. ${ }^{13}$

For each roof facet, shadows of neighboring objects are variable and are considered by calculating the horizon of each pixel in the DSM. All pixels within a defined distance from the pixel of interest are used in this computation. For each pair, a line connecting the two pixels are created and called the profile line. For each profile line an angle is created. If the maximum of all the possible angles is equal to the profile then the point of interest is not within a shaded area. The profile angle $\alpha_{p}$ is defined by Duffie \& Beckman to be the angle through which a plane that is initially horizontal must rotate around the axis of the plane in question in order to include the sun. Mathematically the profile angle is given as:

$$
\tan \alpha_{p}=\tan \alpha_{s} / \cos \left(\gamma_{s}-\gamma\right)
$$

For each sun position, which corresponds to the time to be simulated, the profile angle is checked to determine whether a particular pixel will be set to zero in the reception of beam radiation (its reception of diffuse radiation is, however, still considered) and a new raster is output ${ }^{14}$ (Jochem et al., 2009). The process is scripted as r.horizon which is connected to r.sun in GRASS and which can help run $r$.sun much faster. ${ }^{15}$ In terms of output, it means that the beam component $I_{b}$ has already incorporated shadowing effects of local terrain and nearby objects.

The albedo component is negligible (Carneiro et al., 2009; Nguyen \& Pearce, 2010) except for snow albedo (Andrews \& Pearce, 2011, forthcoming). It makes more sense to include this component when data is 3D and NOT

12 http://manpages.ubuntu.com/manpages/lucid/man1/r.sun.1grass.html

13 http://osgeo-org.1803224.n2.nabble.com/r-sun-and-r-horizon-td3960955.html

14 http://grass.osgeo.org/grass64/manuals/html64_user/r.horizon.html

15 http://grass.osgeo.org/grass64/manuals/html64_user/r.sun.html 
Published as: Ha T. Nguyen and Joshua M. Pearce, "Incorporating Shading Losses in Solar Photovoltaic Potential Assessment at the Municipal Scale” Solar Energy 86(5), pp. 1245-1260 (2012). DOI: http://dx.doi.org/10.1016/j.solener.2012.01.017

2.5D (Mardazeljevic \& Rylatt 2003; Compagnon, 2004). In this case, surface reflectance everywhere is assumed to be 0.2 .

\section{Results and Discussion \\ 4.1.Sky View Factor (SVF)}

Figure 3 is the output of SVF calculated with 32 sectors or an increment of 11.25 degrees in the azimuthal direction and a radius of $20 \mathrm{~m}$. Since the site for this study is but one part of the $1 \mathrm{~km}^{2}$ tile, it is clear why sky obstruction only becomes relevant to the irradiation calculation when it is down to the municipal level. With the terrain (i.e. with a Digital Terrain Model (DTM)) the sky view factor is always 1 or complete visibility of the sky vault with little variation whereas close to the walls of the the building its fluctuation can be very dramatic: from very high to very low and can be down to 0 in the most densely built part of a downtown. Here SVF ranges from 0.83 to 1 . The product from SAGA version 2.0.0 is made fully compatible with ArcGIS 9.3 and GRASS 6.3.0-4 ${ }^{16}$ via the conversion between raster and .asc, the latter is the preferred format of grid file for GRASS (Nguyen \& Pearce, 2010).

\{Insert Fig.3\}

The minimum SVF for the site is 0.83 , which is within the range of values for urban areas investigated by Souza et al. (2003), Carneiro et al. (2009) and Gal et al. (2010). The best sky view, or the maximum of 1 , is not surprisingly reserved for horizontal roof tops.

\subsection{Shading simulation with Hillshade}

Figures 4a-b provided a validation of the shading algorithm by comparing the result generated for the times digital photographs were taken of Clark Hall (August 17, 2010 at 11:48am and again at 2:40pm). The position and the 'line of view' from which the pictures were taken were marked by an oval and a line on the results as seen in Figure 4 . It should be noted that Hillshade and r.sun's own shading algorithm are equivalent. ${ }^{17}$

$$
\text { \{Insert Fig.4a,b\} }
$$

\subsection{Yearly yield}

The monthly rasters were used to compute the yearly yield following:

$$
\left(I_{g b}\right)^{\text {year }}=(1 / 365) * \sum_{i=1}^{12}\left[\left(I_{\text {beam }}\right)^{\text {month }}+s v f *\left(I_{\text {diff }}\right)^{\text {month }}\right] *\left(\kappa_{c}\right)^{\text {month }} *\left(n_{\text {day }}\right)^{\text {month }}
$$

The $\left(I_{g b}\right)^{\text {year }}$ raster, which stores the annual global horizontal irradiance, is calculated and visualized in Figures 5 and 6 for $90 \mathrm{~m}$ and $0.55 \mathrm{~m}$ resolutions respectively. A caution should be made regarding a seemingly high value of $4.36 \mathrm{kWh} /$ $\mathrm{m}^{2}$ in Figure 6: this is an erratic behavior that occurs in a pixel at the edge of a particular roof. It highlights the importance of a proper treatment for roof edges/ breakline (Dorninger \& Pfeifer, 2008; Carneiro et al., 2009). An alternative reason can also be an erroneous aspect or slope value, indicating that the roof extraction/ reconstruction from the LiDAR data should be further refined. In fact this is only a pixel or two among a grid of 1818 by 1818 in the final result.

\section{\{Insert Fig.5\}}

\{Insert Fig.6\}

Both Figures 5 and 6 only show the horizontal incident irradiation and NOT the actual PV module or system output. Higher yield can be collected by putting PV modules at the local optimal tilt angle. However not all the area determined here as PV relevant will be used. The disadvantage of a medium to small roof lying deep in a densely built block is shown by areas with 0 irradiation in Figure 6.

\{Insert Fig.7\}

16http://grass.osgeo.org/grass63/binary/mswindows/native/

17 http://manpages.ubuntu.com/manpages/lucid/man1/r.sun.1grass.html 
Published as: Ha T. Nguyen and Joshua M. Pearce, "Incorporating Shading Losses in Solar Photovoltaic Potential Assessment at the Municipal Scale” Solar Energy 86(5), pp. 1245-1260 (2012). DOI: http://dx.doi.org/10.1016/j.solener.2012.01.017

The scaling down in resolution from $90 \mathrm{~m}$ to $0.55 \mathrm{~m}$ does not only allow a better integration of local sky obstruction, but also reconfirms the effect of low information density (i.e. the use of larger pixel size overestimates global horizontal irradiation) (Cebecauer et al., 2007). Figure7 makes this clear as it shows the annual daily insolation extracted onto the same buildings from two different grids: $90 \mathrm{~m}$ as used by Nguyen \& Pearce (2010) for calculations for solar farms and $0.55 \mathrm{~m}$. Although if a particular roof does not perform well with one grid size, it will not perform well with the other either, the smoothing up or generalization effect of the coarser grid is exposed. On relative terms, the overestimation between $90 \mathrm{~m}$ and $0.55 \mathrm{~m}$ is $28.8 \%$. It is clear from Figure 6 and 7 that higher resolution is necessary to obtain reliable data in the urban context on PV potential.

Somewhat non-intuitively, overestimation due to poor resolution is the highest during the summer, as shown in Figure 8 below. Although the monthly average daily irradiation values (averaged over all the buildings) between two pixel sizes follow the same trend: peaking in the summer and dipping in the winter, the absolute gap between the two trends is the highest between April and August.

\{Insert Fig.8\}

To quantify the impact of shading loss, a comparison between monthly shading integrated beam and non-shading integrated beam is shown in Figure 9.

\{Insert Fig.9\}

Table 1 shows the computation cost and result refinement for each factor, keeping every other factor the same: spatial resolution ( $90 \mathrm{~m}$ or $0.55 \mathrm{~m})$, temporal resolution (15 minutes or 3 minutes), with or without shading.

$\{$ Insert Table 1$\}$

It should be noted that until 2011 no later version of GRASS, up to and including the newly released 6.4.1 version ${ }^{18}$ (April 13th, 2011) can ensure an efficient, crash-free and hassle free simulation better than GRASS 6.3.0-4. ${ }^{19}$

The treatment of irradiation loss by shading is identical to the approach by Levinson et al. (2009) where the underlying assumption is that if the irradiation on that day is closest to the average of the month, then the irradiation loss by shading on that day will also be representative of the month. Hence the mean day is chosen to represent each month, during which shading will run for each daylight hour during that day. The output is a boolean shading raster where a pixel receives a score of 1 if it is occluded by any other pixel and 0 otherwise. The on-hour total, shade fractions of each roofing plane were computed by averaging the score of the plane's cells in the corresponding shadow raster for each hour. The fraction by which shading reduces the irradiation on the planes at that hour is the irradiation loss per plane $\left(\mathrm{I}_{\mathrm{L} / \mathrm{P}}\right)$ :

$$
I_{L / P}=\left(\sum_{i=1}^{n}\left(I_{b}\right)^{i} * s \operatorname{sore}^{i} * A_{\text {pixel }}\right) /\left(\sum_{i=1}^{n}\left(I_{g b}\right)^{i} * A_{\text {pixel }}\right)
$$

What is not clear from the work by Levinson et al. (2009) is whether computation was external to the irradiation simulation. Several things that set the present research apart include (i) the irradiation loss was computed directly with irradiation simulation by unchecking the function within r.sun; (ii) direct normal or beam irradiance is computed at a time step of 3 minutes, instead of 1 hour; and (iii) in the past the irradiation modeling was via online tools, which are only available for the U.S. While here with r.sun any region could be studied.

There is no difference between shading integrated and non-shading diffuse, which confirms the calculation of shade losses in Levinson et al. (2009) to use ONLY direct normal solar irradiances. Figure 9 confirmed the expected trends Siraki et al. (2009) found from monitoring a single building in Montreal that shadow in relative terms is highest in the winter and lowest in the summer. The results plotted in Figure 9 were averaged over 100 buildings in downtown Kingston Ontario, hence a numerical agreement should not be expected. It is further shown that the irradiation in the winter is low enough that the absolute loss in the winter is not as damaging as that in the summer, observed from the opposing trends between shading loss in absolute and relative terms.

18http://grass.osgeo.org/grass64/binary/mswindows/native/

19 http://grass.osgeo.org/grass63/binary/mswindows/native/ 
Published as: Ha T. Nguyen and Joshua M. Pearce, "Incorporating Shading Losses in Solar Photovoltaic Potential Assessment at the Municipal Scale” Solar Energy 86(5), pp. 1245-1260 (2012). DOI: http://dx.doi.org/10.1016/j.solener.2012.01.017

In Australia, although detailed data on the effects of shading are not available, Rae et al. (1999) have listed sources to show that the impact of shading upon rooftop PV output to produce only a $2 \%$ drop. For Kingston, shading results in a reduction of $25 \%$ in PV output, averaged over 12 months. It is also noted that the result is excluding in-row shading when the actual panels are installed. With hourly time steps, the losses in PV output due to shading averaged over the year and averaged over only the summer months are $27 \%$ and $17 \%$ respectively. The $17 \%$ shading loss during the summer should be self explanatory from Figure 9, which shows the opposing trends between shading loss in absolute and relative terms and confirms the findings of Siraki et al. (2009) from monitoring buildings in Montreal. Thus by simulating only the summer months and at hourly time steps one can get within $2 \%$ of the average month irradiation loss by shading over the year obtained by 3 minute time steps simulations for all twelve months.

\subsection{Selection of candidate roof sections for PV installation}

To optimize the performance of PV modules it is best to orient them due south and tilt them within 15 degrees of the local latitude (Duffie \& Beckman, 2001). This means that the first two criteria to select candidate roof sections are (i) azimuth angles from southeast to southwest i.e. 90 degrees to 270 degrees due north and (ii) slope between 0 degrees and 60 degrees (the local latitude of Kingston is 44 degrees) (Carneiro et al., 2009).

As shown by the literature (Paidipati et al., 2009) and from section 4.3, shading loss is the next important limiting factor for the uptake of solar PV in the urban environment due to its impact on life cycle economics.

There is no readily available defined a rule of thumb for the acceptable length of shadow duration for PV deployment. Although it should be pointed out that with the new generation of bypass diode enabled modules, the tolerance of PV cells up to a certain number of hours in occlusion has been greatly enhanced (Norton et al., 2010) and the rise of microinverters allows arrays to produce output from illuminated panels rather than having strings eliminated from a single shaded module. Thus it is possible to generate a series of irradiation loss maps for 12 months for a given region.

\section{\{Insert Fig. 10\}}

In addition, it is possible to provide a visualization of roof areas with suitable aspect and slope $A_{p v}$, which is shown in Fig.10. It is clear for this site that aspect is the dominant criterion. That means (i) the data has to be precise or any significant error in point cloud processing would lead to error in aspect analysis; and (ii) the construction of a building in a neighborhood, especially in the more densely populated areas, will have an effect on the uptake of solar energy both of its own and of the surrounding buildings. This will add an important factor into consideration, that of density and orientation of houses, for city planners, for which LiDAR data analysis in general and the methodology of this paper is being demonstrated to be of great assistance.

\section{\{Indert Fig. 11\}}

$\left(A_{p v}\right)^{\text {site }}$ is defined to be the true area of the roof sections selected as suitable for installing PV. ( $\left.A_{\text {roof }}\right)^{\text {site }}$ is defined to be the true area of all the roofs considered in the simulation i.e. it is the result of the process described in section 3.1. $\left(A_{\text {projroof }}\right)^{\text {site }}$ is the projected area of all the roofs considered in the simulation and is calculated directly from the roofprint shapefile. In this example site, if only the slope and aspect criteria were taken into account $\left(A_{p v}\right)^{\text {site }}$ was found to be $22,086 \mathrm{~m}^{2},\left(A_{\text {roof }}\right)^{\text {site }}$ is $37,384 \mathrm{~m}^{2}$, and $\left(A_{\text {projroof }}\right)^{\text {site }}$ was found to be $39,246 \mathrm{~m}^{2}$. Wiginton et al. (2010) and Nguyen \& Pearce (2011) claimed that the ratio of $\mathrm{r}_{\mathrm{pv}}=\left(A_{p v}\right)^{\text {site }} /\left(A_{\text {projroof }}\right)^{\text {site }}$ is $0.30-0.33$ for a region of the same city with primarily residential uses. For the latter, all tilted roofs were assumed a universal tilt angle of $45^{\circ}$. When tilt angles were taken as true from the surface and hence vary from pixel to pixel, this ratio $r_{p v}$ for the present case is 0.56 . Further $r_{\text {roof }}$ or $\left(A_{\text {roof }}\right)^{\text {site }} /\left(A_{\text {projroof }}\right)^{\text {site }}$ was found to be 0.95 . Both are within the range reported from previous literature (Wiginton et al., 2010).

Carneiro et al. (2009) mentioned additional criteria such as: i) only $80 \%$ of horizontal surfaces of roofs are computed due to the inclination of panels and, ii) areas that have a SVF smaller than $60 \%$ should also be discarded, in order to consider the effects generated by the mutual shadings casted by buildings that otherwise would not be addressed. As shown in Figure 3 the minimum SVF value for the case study site is 0.83 . In addition the minimum roof area is $71 \mathrm{~m}^{2}$. Hence these additional conditions are more suitable for a residential areas rather than a downtown as analyzed here. Another threshold mentioned in the literature is the minimum annual daily GHI for solar systems to be mounted on roofs is $2.74 \mathrm{kWh} / \mathrm{m}^{2}$ (Compagnon, 2004). However this choice is arbitrary and was not justified. In the U.S., shading other than tree shading reduces the PV access factor for residential houses by $90 \%$ in both warm and cool climates and by $65-75 \%$ for commercial buildings in both warm and cool climates (Paidipati et al., 2008). Again to apply this rule it 
Published as: Ha T. Nguyen and Joshua M. Pearce, "Incorporating Shading Losses in Solar Photovoltaic Potential Assessment at the Municipal Scale” Solar Energy 86(5), pp. 1245-1260 (2012). DOI: http://dx.doi.org/10.1016/j.solener.2012.01.017

is necessarily to classify the buildings according to civic use purposes and there is a clear potential for a wide variation in a given region.

$r_{p v}$ can be refined further since (i) the roof extent has been trimmed down twice:

the first time by the buffer to get rid of the edges and the second time by the side effect of roof segmentation; and (ii) although efforts have been made to eliminate the vegetation points from roof points, noise persists where the canopy lies directly on the roof face or where the laser shots did not reach the surface of the roof and hence the pulses do not represent roof surface. In such cases vegetation pulses possess the same statistical characteristics with the point clouds (Jochem et al., 2009). In addition, although trees are not overly abundant in the area as observed from the aerial photos, there is still an effect of shading from trees, but which has been left for future work. Finally, it is important to note the error within 5 degrees of the roof angle after reconstruction could have erroneously rendered some pixels not suitable for PV.

As for $r_{\text {roof }}$, on one hand the result of 0.95 again reflects the trimmed extent of roof after reconstruction. In reality the installation of PV panels always takes into account the structure of the roof and roof surface objects and hence rarely covers the whole roof. On the other hand, this is at best only typical for the downtown areas or where flat roofs are dominant such as the present case happens to be. When more sloped roofs are available such as in a residential area $r_{\text {roof }}$ is expected to shift accordingly.

\section{Future Work}

These results allow the stakeholders (solar PV engineers, municipal governments, urban planners, utilities operators) to answer the questions raised by Carneiro et al. (2009): Can we build denser cities without decreasing the potential for solar architecture? What is the incidence of beam versus diffuse insolation contributions in typical urban texture? A possible start is by establishing a set of parameters that address the solar admittance of the urban fabric. These are: (a) the area of roofs suitable for installing PV modules, also expressed as a ratio to the total area of roofs; (b) the irradiation density, i.e. the incident energy per $\mathrm{m}^{2}$; (c) an urban irradiation density, defined as the total net incident irradiation on urban roofs divided by the population. This last parameter does not represent a measure that can be converted into useful energy and is only possible if data is available, which is a rare case due to urban gentrification and the trend of downtown areas becoming increasingly dominated by commercial properties rather than permanent urban dwellers. However it will give an indication by proxy of a low hanging benefit for installing PV on rooftops in the city.

Compagnon (2004) listed several applications towards sustainable urban design that can be built around or in combination with this simulation:

- Assessment of the possible consequences of urban planning guidelines or regulations on solar and daylight availability prior to implementation

- Quantification of the impact of new urban developments/ tree planting compaigns (Levinson et al., 2009) on existing buildings or collector systems

- Irradiation and illuminance calculations in open spaces either to improve solar and daylight access or to ensure sufficient shading.

The expansion of the presented workflow to application in a given city can be best exemplified by such programs as POLIS $^{20}$ (Identification and mobilisation of Solar Potentials via Local strategies) and that in New York City ${ }^{21}$ completed in 2010. While the capability of the workflow can be tested in terms of integrating the physical structure of a building or a group of buildings and their positions within the urban terrain with local solar development, its functionality can give rise to a new computer system devoted to support solar access decision making in a sustainable urban design perspective such as the case of POLIS and Townscope II (Teller \& Azar, 2001).

\subsection{Performance comparisons with existing packages}

Several authors have tried to demonstrate the use of such packages as Radiance ${ }^{22}$ (Mardaljevic \& Rylatt, 2003; Compagnon, 2004; Kamfp et al., 2010) and Heliodon2TM ${ }^{23}$ (Beckers et al., 2010; Merino et al., 2010) and situate the use of ray tracing techniques in urban solar energy simulation. This was possible because the data for those projects are

\footnotetext{
20 http://www.polis-solar.eu

21 http://www.cuny.edu/about/resources/sustainability/solar-america/map.html

22 http://radsite.lbl.gov/radiance/

23 http://www.heliodon.net/heliodon/index.html
} 
Published as: Ha T. Nguyen and Joshua M. Pearce, "Incorporating Shading Losses in Solar Photovoltaic Potential Assessment at the Municipal Scale” Solar Energy 86(5), pp. 1245-1260 (2012). DOI: http://dx.doi.org/10.1016/j.solener.2012.01.017

fully 3D whereas the data here is $2.5 \mathrm{D}$. The 2.5D nature limits the consideration to only roof mounted systems, but not building integration and to direct and diffuse beam components, but not reflectance. When both 2.5D and 3D data for the same site is available, future work can include a comparison in terms of the robustness and accuracy between these various modules e.g. rtrace (Radiance) and r.sun is useful in determining the optimal choice for a methodology or software in simulating irradiation at the meso and microscales.

\subsection{Interpolation for daily Linke turbidity values}

The methodology developed here introduces the Linke turbidity values for the local coordinates of a given city (Kingston) into the module r.sun. These monthly Linke turbidity values were the results of data fusion between highly accurate, location specific measurements and grid average values for other quantities, which were later transformed into monthly $\mathrm{T}_{\mathrm{L}}$ maps (Remund et al., 2003) over the world. Although monthly values of the Linke turbidity factor worldwide are useful, the dynamics of airborne aerosols in the atmosphere could yield significant variability on the daily turbidity pattern (Polo et al., 2009). A new script developed for interpolating $\mathrm{T}_{\mathrm{L}}$ down to daily values was developed and is being tested, which may be of use. Finally, the integration of g.linkeinterp ${ }^{24}$ into r.sun can provide another refinement for the simulation in the future.

\subsection{Sensitivity analysis on $r_{p v}$ and $r_{\text {roof }}$}

Previous literature has returned a wide range of values for $r_{p v}$ and $r_{\text {roof }}$. However, these ratios were computed under a great variety of locations and methods and hence it is impossible to establish a rule of thumb into a calibration between loss in accuracy for GHI estimation caused by the sophistication of roof modeling (Beckers et al., 2010). Beckers et al. discovered that going from detailed roof modeling to just using projected roof area results in a decrease of $33 \%$ in summer energy values, an increase of $6 \%$ in winter energy values and an overall increment of $1 \%$ in annual GHI. Hence, by repeating the same process on the same dataset for other parts of the city of Kingston, it is possible to generate at least local rule of thumb for a calibration between loss in accuracy for GHI estimation caused by simplicity in roof modeling.

In order to evaluate a municipal district for some form of policy intervention (e.g. a feed in tariff), the following can be used as a basis. First the buildings are classified according to types of house (residential/ commercial; detached and semi-detached/ townhouses and rowhouses/ high rise). Then the values determined from the methodology outlined in this paper can be refined by a multiplication with installation ratios proposed by Paidipati et al. (2008) and Ordonez et al.(2010). Then from the perspective of a PV developers, the number of PV modules can be calculated by adjusting the row spacing (Carneiro et al., 2009; Ordonez et al., 2010).

\section{Conclusions}

This study took the conceptual and methodological frameworks proposed by Ratti et al. (2005), Jochem et al. (2009) and Carneiro et al. (2009) and exceeds them by (i) incorporating both terrain and near surface shadowing effects on the beam component; (ii) scaling down the diffuse components of global irradiation; and (iii) introducing the parallel commands in the open source and free access GRASS for those who have no access to ArcGIS.

This study has a smaller scale than those in California (Levinson et al., 2009), but is more solid in the approach: semiautomatic and easy to upgrade or correct (no hand drawn areas); open source (in the shading calculation); detailed (neither Levinson et al. nor recent authors on the same topic explain as clearly the operation and choice of the Hillshade function or offers an open source equivalent) and provides rules of thumb for PV system design at the municipal level.

The scale of interest was the meso scale where such factors of the urban texture as sky view factor, near object shading comes into play and hence a more complicated methodology was created to handle the higher detail requirement. Out of a two dimensional extent of approximately $40,000 \mathrm{~m}^{2}$ in building coverage in an example of Kingston, ON, 22,000 $\mathrm{m}^{2}$ of roof area was found to be suitable and potentially optimal for the purpose of solar PV installations. The criteria used in the example, concerning aspect, slope and shadow effect can be relaxed or made more constrained. Additional constraints can be added and results instantly visualized, which demonstrates the flexibility and adaptability of the novel workflow developed in this paper.

With higher integration of urban texture, but without such noise as antenna, chimneys and HVACs, the global horizontal

24 http://trac.osgeo.org/grass/browser/grass-addons/raster/r.sun.tools/g.linke_by_day.py 
Published as: Ha T. Nguyen and Joshua M. Pearce, “Incorporating Shading Losses in Solar Photovoltaic Potential Assessment at the Municipal Scale” Solar Energy 86(5), pp. 1245-1260 (2012). DOI: http://dx.doi.org/10.1016/j.solener.2012.01.017

irradiation is lower by $30 \%$ with the highest overestimation occurring in the summer. On one hand this can be refined further by improving the surface generation scripts, using higher quality LiDAR data and integrating vegetation. On the other hand the robustness of r.sun as capable of working with different levels of surface complexity has been confirmed. Further the trade off of each computation option (spatial resolution, time step and shading effect) has been quantified. The results suggest that by simulating only the summer months and at hourly steps the results are within $2 \%$ of the average month irradiation loss by shading over the year.

\section{Acknowledgements}

The authors would like to acknowledge helpful discussions with R. Harrap and R. Andrews.

\section{References}

Beckers, B., Rodriguez, D., Antaluca, E., Batoz, J-L. 2010. About solar energy simulation in the urban framework: The model of Compiegne. In: 3rd International Congress Bauhass SOLAR. 10 - 11 November. Erfurt, Germany.

Blanco-Muriel, M., Alarcon-Padilla, D.C., Lopez-Moratalla, T., Lara-Coira, M. 2001. Computing the solar vector. Solar Energy 70(5), $431-441$.

Branker, K., Pearce, J.M. (2010). Financial Return for Government Support of Large-ScaleThin-Film Solar Photovoltaic Manufacturing in Canada. Energy Policy 38, 4291-4303.

Budin, R., Budin, L. 1982. A mathematical model for shading calculations. Solar Energy 29(4), 339 - 349.

Carneiro, C., Morello, E., Desthieux, G. Assessment of Solar Irradiance on the Urban Fabric for the Production of Renewable Energy using LIDAR Data and Image Processing Techniques. AGILE Conf. 2009, 83 - 112.

Cebecauer, T., Huld, T., Suri, M. 2007. Using high resolution digital elevation model for improved PV yield estimates. In: proceedings of the 22nd European Photovoltaic Solar Energy Conference Italy, pp. 3353 - 3357.

Compagnon, R. 2004. Solar and daylight availability in the urban fabric. Energy and Buildings 36, 321 - 328.

de Vries, B.J.M., van Vuuren, D.P., Hoogwijk, M.M. 2007. Renewable energy sources: Their global potential for the first-half of the 21st century at a global level: An integrated approach. Energy Policy, 35(4), 2590 - 2610.

Doty, G. N., D. L. McCree, J. M. Doty, F. D. Doty. (2010). Deployment Prospects for Proposed Sustainable Energy Alternatives in 2020, ASME 2010 Conf. Proc. 171(1), pp. 171-182.

Duffie, J.A., Beckman, W.A. 2001. Solar engineering of thermal processes. 3rd Edition. Wiley-Interscience.

d’Estaintot, T. (2000). "European Commission-supported R\&D activities in the field of photovoltaics". Proceedings of the 28th IEEE Photovoltaic Specialists Conference (15-22 September, Anchorage), 1734-1735.

European Photovoltaic Industry Association. (2003). Photovoltaic Bulletin, 2003(3), 6-8.

Gal, T., Lindberg, F., Unger, J. 2009. Computing continuous sky view factors using 3D urban raster and vector databases: comparison and application to urban climate. Theoretical and Applied Climatology 95, 111-123.

Green, M.A., Emery, K., Yishikawa, H., Warta, W. (2010). Solar cell efficiency tables (Version 35). Short communication. Progress in Photovoltaics: Research and Applications, 18(2), 144-150, doi: 10.1002/pip.974.

Grena, R. 2008. An algorithm for the computation of the solar position. Solar Energy 82, 462 - 470.

Hantzschel, J., Goldberg, V., Bernhofer, C. 2005. GIS-based regionalisation of radiation, tmeperature and coupling measures in complex terrain for low moutain ranges. Meteorological Applications 12, 33 - 42. 
Published as: Ha T. Nguyen and Joshua M. Pearce, “Incorporating Shading Losses in Solar Photovoltaic Potential Assessment at the Municipal Scale” Solar Energy 86(5), pp. 1245-1260 (2012). DOI: http://dx.doi.org/10.1016/j.solener.2012.01.017

Helm, D. (2005). The assessment: the new energy paradigm. Oxford Review of Economic Policy 21.1, 1-18.

Hoffman, W. (2006). PV solar electricity industry: Market growth and perspective. Solar Energy Materials and Solar Cells, 90 (18-19), 3285 - 3311. 14th International Photovoltaic Science and

Engineering Conference.

Hofierka, J., Kanuk, J. 2009. Assessment of photovoltaic potential in urban areas using open source solar radiation tools. Renewable Energy 34, 2206 - 2214.

Hofierka, J., Suri, M. 2002. The solar radiation model for open source gis: implementation and applications. Proceedings of Open source GIS - GRASS users conference 2002, Trento, Italy.

Horn, B.K.P. 1981. Hill shading and the Reflectance map. Proceedings of the IEEE, 69(1), 14 - 57.

International Energy Agency. (2010). International Energy Agency (IEA), Technology Roadmap - Solar Photovoltaic Energy, October, 2010, pp.1-48.

Jochem, A., Hofle, B., Rutzinger, M., Pfeifer, N. 2009. Automatic roof plan detection and analysis of airborne lidar point clouds for solar potential assessment. Sensors 9, $5241-5262$.

Kenny, R., Law, C., Pearce, J.M. 2010. Towards Real Energy Economics: Energy Policy Driven by Life-Cycle Carbon Emission, Energy Policy 38, 1969-1978.

Levinson, R., Akbari, H., Pomerantz, M., Gupta, S. 2009. Solar access of residential rooftops in four Californian cities. Solar Energy 83, 2010 - 2035.

Mardaljevic, J., Rylatt, M. 2003. Irradiation mapping of urban environments: an image-based approach. Energy and Buildings 35, $27-35$.

Marvin, S., Graham, S., Guy, S. (1999). Cities, regions and privatised utilities. Progress in Planning. 51(2), 91-165.

Marvin, S. Guy, S. (1997). Infrastructure provision, development processes and the co-production of environmental value. Urban Studies. 34(12), 2023-36.

Matzarakis, A. , Matuschek, O. 2009. Estimation of Sky View Factor in urban environments. Proceedings METTOOLS VII. Hamburg, Germany.

Merino, L., Antaluca, E., Akinoglu, B., Beckers, B. 2010. Solar Energy Inputs Estimation for Urban Scales Applications. In: 8th International Conference on System Simulation in Building, 13 - 15 December. Liege, Belgium

Michalsky, J.J. 1988. The astronomical almanac's algorithm for approximate solar position (1950 - 2050). Solar Energy 40(3), $227-235$.

Mints, P. (2011). The 12-step solar program: Towards an incentive-less future, Navigant Consulting. Accessed January 19, 2011, on ElectoIQ, http://www.electroiq.com

Monstad, J. (2007). Urban Governance and the Transition of Energy Systems: Institutional Change and Shifting Energy and Climate Policies in Berlin. International Journal of Urban and Regional Research. 31(20), 326 - 343.

Neteler, M., Mitasova, H. 2008. Open source GIS: a GRASS GIS approach. 3rd Edition.

The International Series in Engineering and Computer Science. Springer, New York.

Nguyen, H.T., Pearce, J.M. 2011. Towards Automated Quantification of Solar Photovoltaic Potential in Large Urban Areas for City-based Electric Utility Planning. Proceedings of the International Conference 2011 on Spatial Planning and Sustainable Development. Kanazawa, Japan A31-3 (2011). 
Published as: Ha T. Nguyen and Joshua M. Pearce, “Incorporating Shading Losses in Solar Photovoltaic Potential Assessment at the Municipal Scale” Solar Energy 86(5), pp. 1245-1260 (2012). DOI: http://dx.doi.org/10.1016/j.solener.2012.01.017

Nguyen, H.T., Pearce, J.M., Harrap, R., Barber, G. 2011. The Application of LiDAR to Assessment of Rooftop Solar Photovoltaic Deployment Potential on a Municipal District Unit. To be published.

Nguyen, H.T., Pearce, J.M. 2010. Estimating Potential Photovoltaic Yield with r.sun and the Open Source Geographical Resources Analysis Support System. Solar Energy 84, 831-843.

Norton, B., Eamesb, P.C., Mallickc, T.K., Huang, M.J., McCormack, S.J., Mondol, J.D., Yohanis, Y.G. 2010. Enhancing the performance of building integrated photovoltaics . Solar Energy (In press).

Ordonez, L., Jadraque, E., Alegre, J., Martinez, G. Analysis of the photovoltaic solar energy capacity of residential rooftops in Andalusia (Spain). Renewable and Sustainable Energy Reviews 10, 2122 - 2130.

Paidipati, J., Frantzis, L., Sawyer, H., Kurrasch, A. Rooftop Photovoltaics Market Penetration Scenarios. Subcontract Report NREL/SR-581-42306. http://www.gsyenergy.com/documents/Final_Report_PV_MarketsNREL_US_EG.pdf

Pearce, J.M. (2002). "Photovoltaics — A Path to Sustainable Futures". Futures. 34(7), 663-674.

Perpinan, O., Lorenzo, E., Castro, M.A., Eyras, R. 2008. On the complexity of radiation models for PV energy production calculation. Solar Energy 82(2), 125 - 131.

Pitman, C., Vant-Hull, L.L. 1978. Errors in locating the Sun and their effect on solar intensity predictions. In Meetin of the American Section of the International Solar Energy Society. Denver, USA.

Polo, J., Zarzalejo, L.F., Martín, L., Navarro, A.A.,Marchant, R. 2009. Estimation of daily Linke turbidity factor by using global irradiance measurements at solar noon. Solar Energy 83(8), 1177 - 1185.

Price, S., Margolis, R. (2008) Solar technologies market report, Energy Efficiency \& Renewable Energy, US Department of Energy, January 2010, pp. 1-131.

Ratti, C., Baker, N., Steemers, K. 2005. Energy consumption and urban texture. Energy and Builings 37, 762 - 776.

Reda, I., Andreas, A. 2004. Solar Position Algorithm for Solar Radiation Applications. Solar Energy $76(5), 577$ - 589.

Remund J., Wald L., Lefevre M., Ranchin T., Page J. 2003. Worldwide Linke turbidity information. Proceedings of ISES Solar World Congress. 16 - 19 June. Goteborg, Sweden.

Renewable Energy Policy network for the 21st century (REN21). (2008). Renewables 2007 Global Status Report, pp. 154.

Spencer, J.W. 1971. Fourier series representation of the position of the Sun. Search 2(5).

Solar Energy at the Urban Scale proceedings. http://www.utc.fr/seus/iso_album/abstract_seus.pdf 25-26th May 2010, Compiegne, France.

Souza, L. C. L., Rodrigues, D. S., Mendes, J. F. 2003. A 3d-gis extension for sky view factors assessment in urban environment. - Proceedings of the 8th International Conference on Computers in Urban Planning and Urban Management CUPUM'03, Sendai, Japan.

Suri, M., Hofierka, J. 2004. A new gis-based solar radiation model and its application to photovoltaic assessments. Trans. GIS 2004, 8, 175-190.

Teller, J., Azar, S. 2001. Townscope II: A computer system to support solar access decision making. Solar Energy 70(3), $187-200$.

Wahschning, V., Hanitsch, R. 1995. Shade calculations in photovoltaic systems. In ISES Solar World Conference. Harare, Zimbabwe. 
Published as: Ha T. Nguyen and Joshua M. Pearce, "Incorporating Shading Losses in Solar Photovoltaic Potential Assessment at the Municipal Scale” Solar Energy 86(5), pp. 1245-1260 (2012). DOI: http://dx.doi.org/10.1016/j.solener.2012.01.017

Walvaren, R. 1978. Calculating the position of the Sun. Solar Energy 20, 393 - 397.

Rae, M.R. 1, W.E. Lilley 1 and L.J. Reedman. 2009. Estimating the Uptake of Distributed Energy in an Urban Setting. In: Proceedings to 18th World IMACS / MODSIM Congress, Cairns, Australia.

http://www.mssanz.org.au/modsim09/F4/rae.pdf

Wiginton, L.K., Nguyen, H. T., Pearce, J.M. 2010. Quantifying Solar Photovoltaic Potential on a Large Scale for Renewable Energy Regional Policy. Computers, Environment and Urban Systems 34, 345-357.

Yousef, A.A. 2010. The Use of geographical information systems for 3D Urban models reconstruction from Aerial Lidar data. Doctorate thesis.

Table 1: Trade-offs of computation costs as a function of simulation options

\begin{tabular}{|c|c|c|c|}
\hline \multirow{2}{*}{\multicolumn{2}{|c|}{ Simulation option }} & \multirow{4}{*}{$\begin{array}{l}\text { Computation cost } \\
10 \text { minutes } \\
10 \text { minutes but on an extent of } \\
1 / 420,000 \text { of the } 90 \mathrm{~m} \text { grid }\end{array}$} & \multirow{4}{*}{$\begin{array}{l}\text { Result refinement } \\
\text { A refinement of } 28.8 \% \text { in } \\
\text { annual daily insolation (Figure } \\
\text { 7) }\end{array}$} \\
\hline & & & \\
\hline \multirow{2}{*}{$\begin{array}{l}\text { Spatial } \\
\text { resolution }\end{array}$} & $90 \mathrm{~m}$ & & \\
\hline & $0.55 \mathrm{~m}$ & & \\
\hline \multirow{2}{*}{$\begin{array}{l}\text { Temporal } \\
\text { resolution }\end{array}$} & 15 minutes & 10 minutes & \multirow{2}{*}{$\begin{array}{l}\text { Not a significant improvement } \\
\text { from } 15 \text { minutes downwards as } \\
\text { inspected in the result (not } \\
\text { shown here) and suggested by } \\
\text { Perpinan et al. (2008). }\end{array}$} \\
\hline & 3 minutes & 40 minutes & \\
\hline \multirow[t]{2}{*}{ Shading } & Yes & 8 minutes & \multirow{2}{*}{$\begin{array}{l}\text { A refinement of } 25 \% \text { in average } \\
\text { monthly mean insolation }\end{array}$} \\
\hline & No & 1 minute & \\
\hline
\end{tabular}

Figure Captions 
Published as: Ha T. Nguyen and Joshua M. Pearce, "Incorporating Shading Losses in Solar Photovoltaic Potential Assessment at the Municipal Scale" Solar Energy 86(5), pp. 1245-1260 (2012). DOI: http://dx.doi.org/10.1016/j.solener.2012.01.017

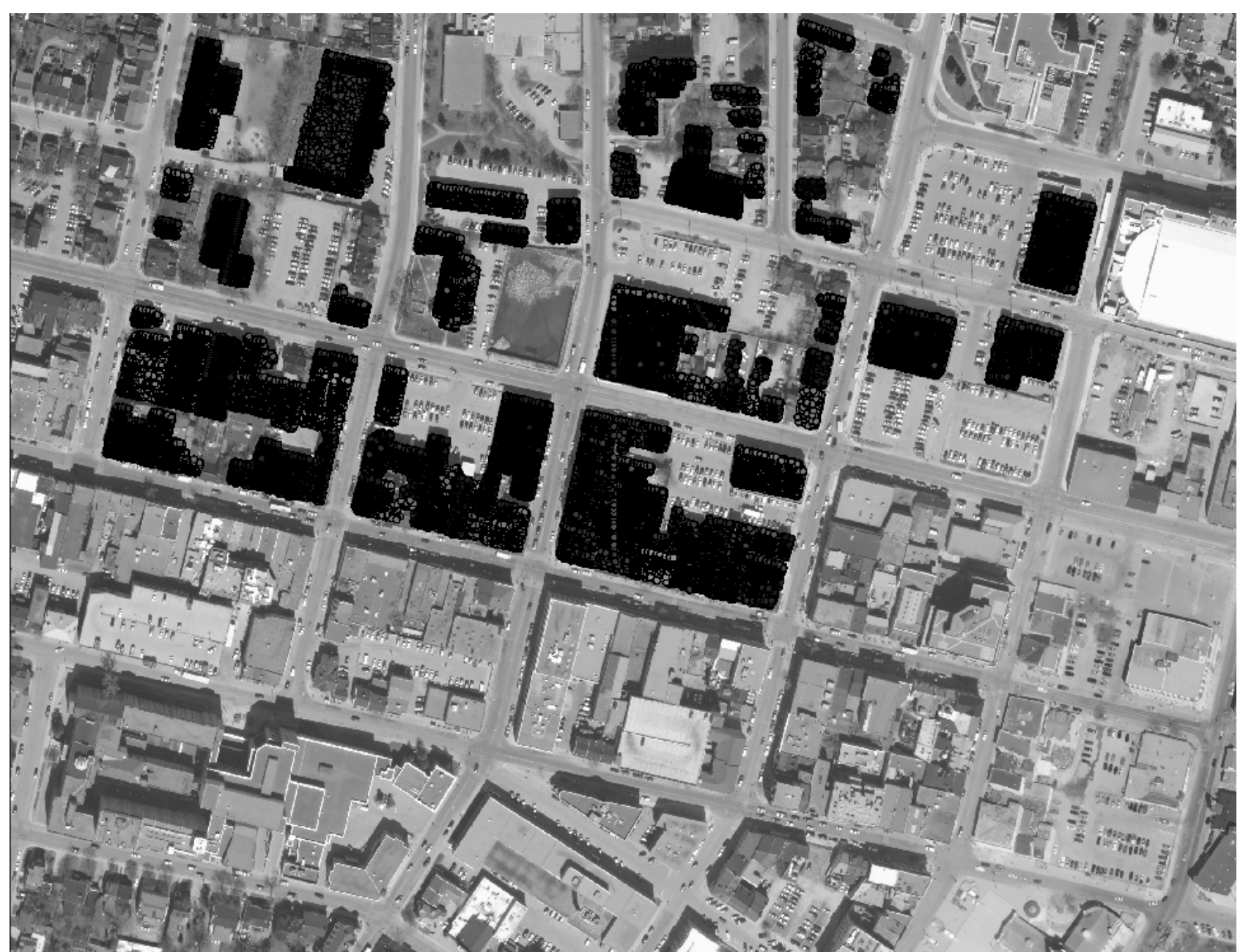

Figure 1. Simulation site. The point clouds correspond to the buildings included in the following simulation. 
Published as: Ha T. Nguyen and Joshua M. Pearce, "Incorporating Shading Losses in Solar Photovoltaic Potential Assessment at the Municipal Scale” Solar Energy 86(5), pp. 1245-1260 (2012). DOI: http://dx.doi.org/10.1016/j.solener.2012.01.017

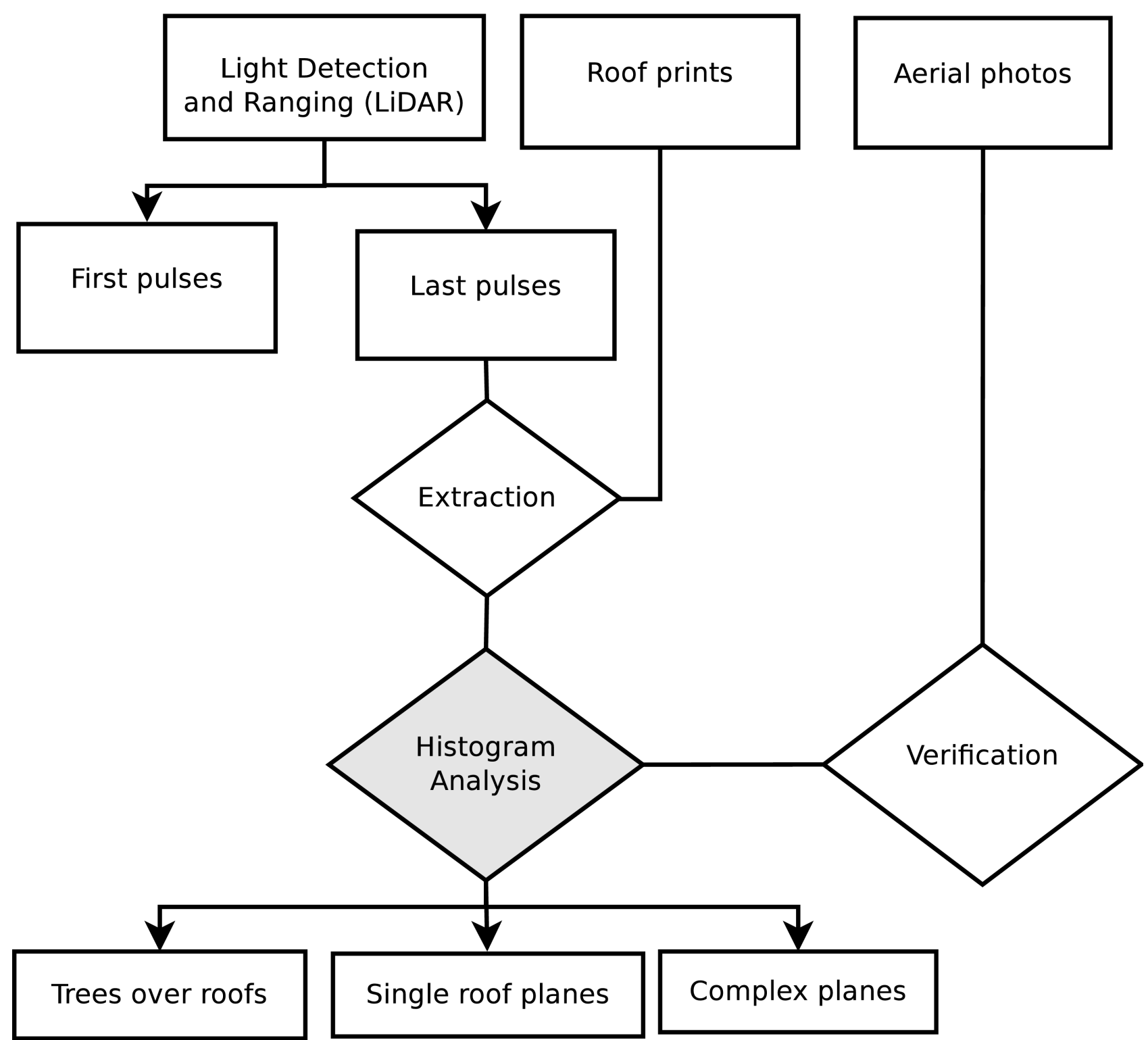

Figure 2a. Data processing part 1: Classification of LiDAR points by the objects to which they corresponded. 
Published as: Ha T. Nguyen and Joshua M. Pearce, "Incorporating Shading Losses in Solar Photovoltaic Potential Assessment at the Municipal Scale” Solar Energy 86(5), pp. 1245-1260 (2012). DOI: http://dx.doi.org/10.1016/j.solener.2012.01.017

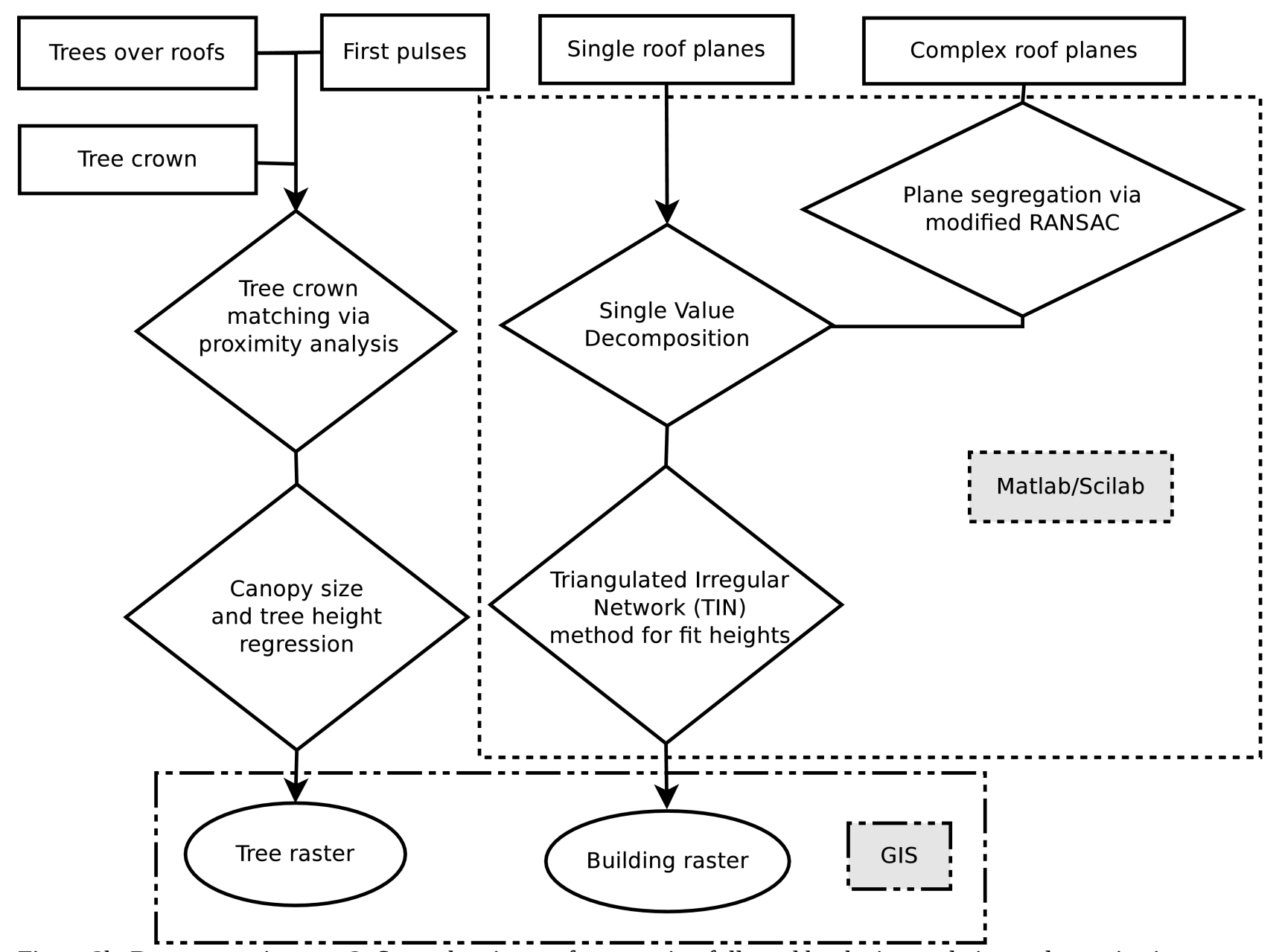

Figure 2b. Data processing part 2: Steps showing roof segregation followed by the interpolation and rasterization. 
Published as: Ha T. Nguyen and Joshua M. Pearce, "Incorporating Shading Losses in Solar Photovoltaic Potential Assessment at the Municipal Scale” Solar Energy 86(5), pp. 1245-1260 (2012). DOI: http://dx.doi.org/10.1016/j.solener.2012.01.017

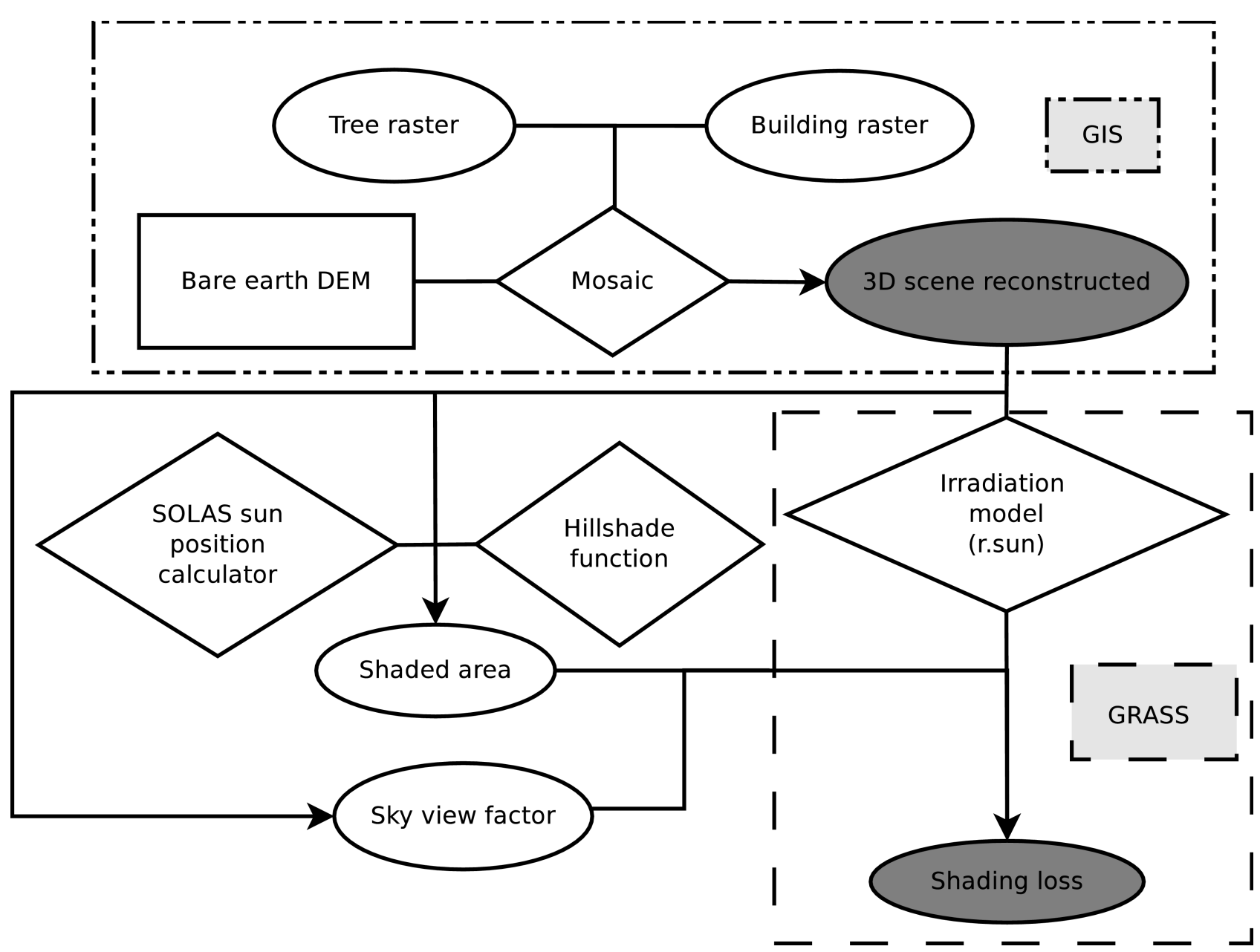

Figure 2c. Data processing part 3: Final scene construction and irradiance $\overline{m o d e l i n g .}$

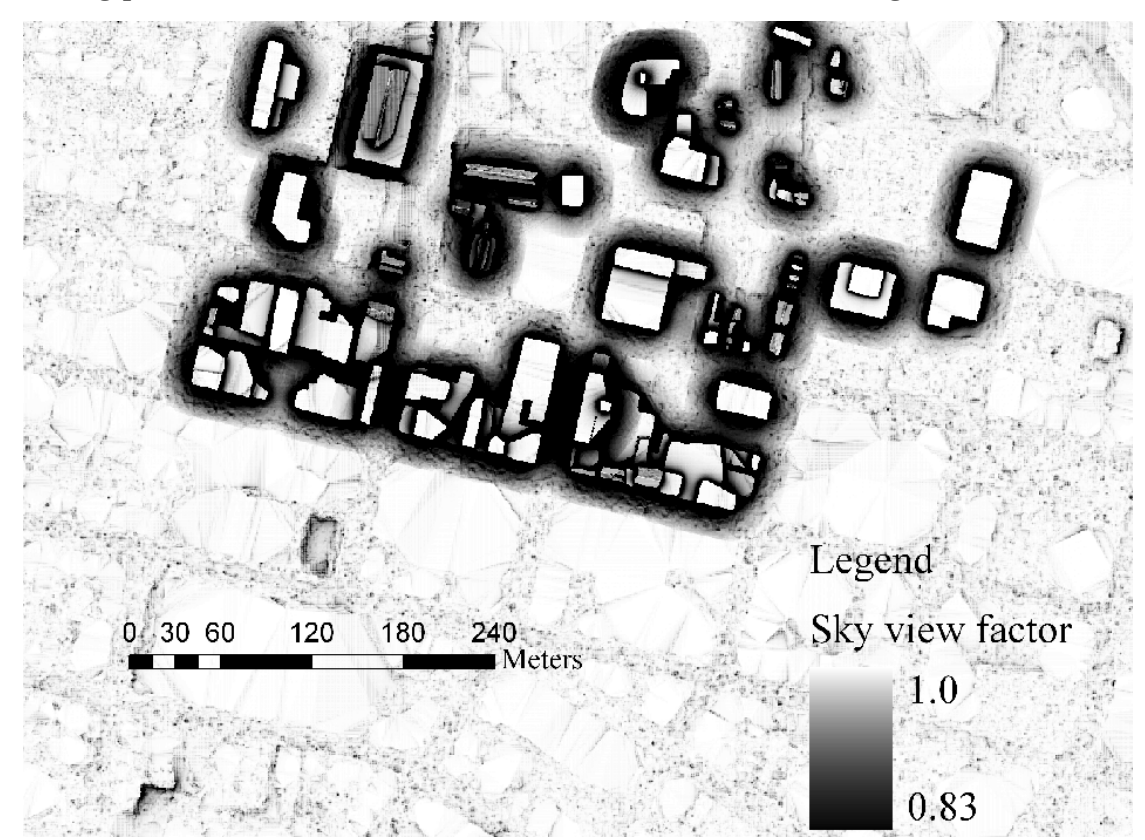

Figure 3. The output of the Sky View Factor (SVF) calculated with 32 sectors or an increment of 11.25 degrees in the azimuthal direction and a radius of $20 \mathrm{~m}$. Taller and flat buidings appear to have the biggest SVF (i.e. total open view to the sky), while the adjacent ground and lower, smaller buildings do not, hence a lower SVF or a darker tone. 
Published as: Ha T. Nguyen and Joshua M. Pearce, "Incorporating Shading Losses in Solar Photovoltaic Potential Assessment at the Municipal Scale” Solar Energy 86(5), pp. 1245-1260 (2012). DOI: http://dx.doi.org/10.1016/j.solener.2012.01.017

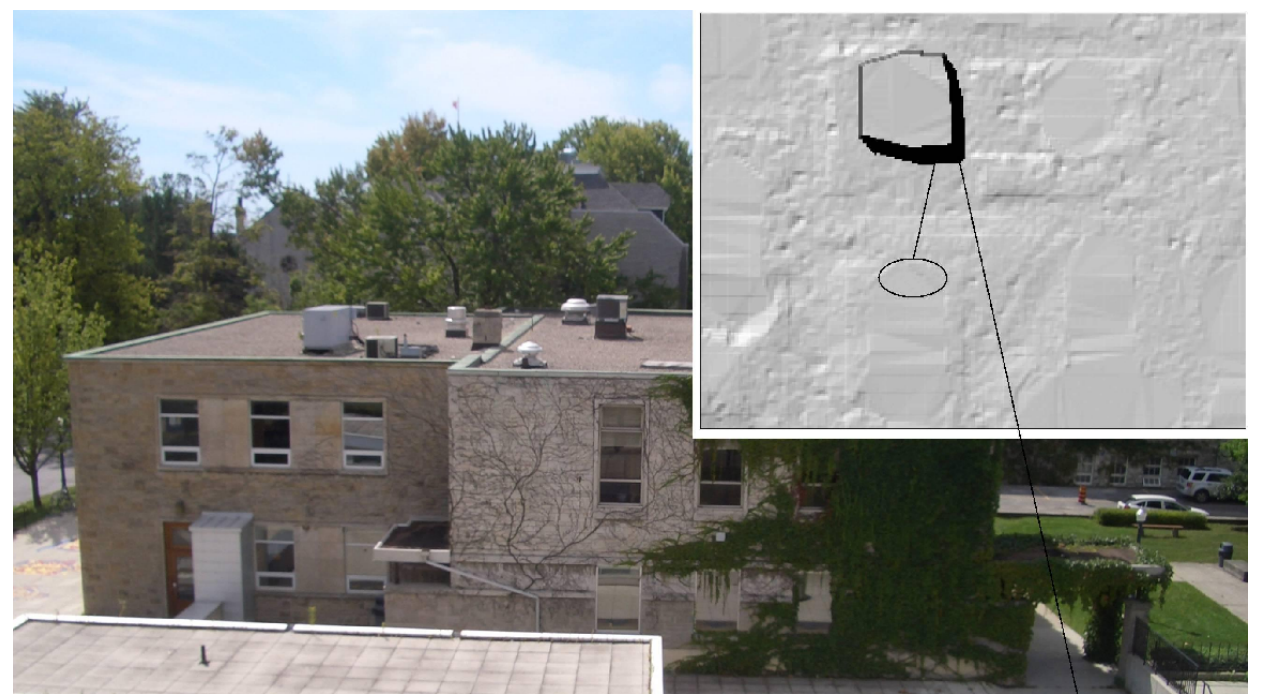

Figure 4a. Original digital photograph of Clark Hall at 11:46am August 17, 2010. The shading extent is pointed out between the original photo and the inset simulated result. In the inset, the position from which the photo was taken is represented by an oval.

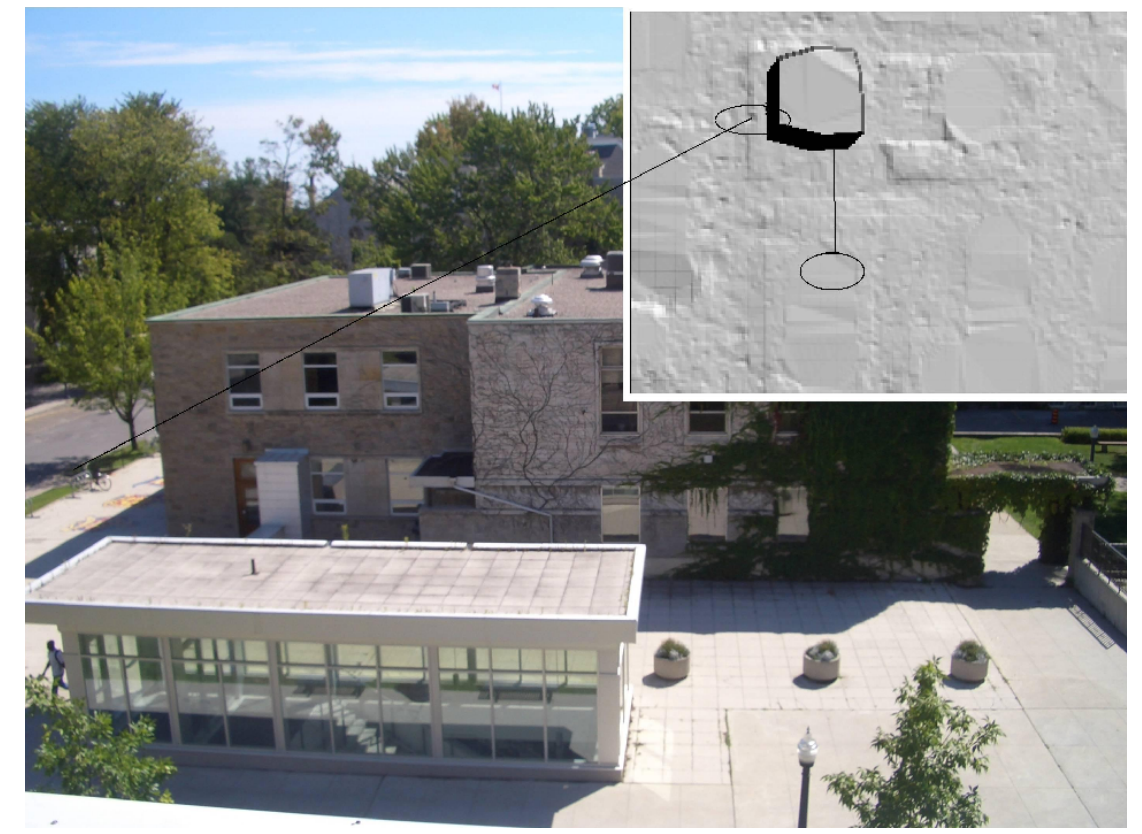

Figure 4b. Original digital photograph of Clark Hall at 2:40pm August 17, 2010 with inset of simulated result. The important agreement between the original photo and the simulated result is shown as the shadow has not extented over the steps down to the biking lane (to the left of the original digial photograph). 
Published as: Ha T. Nguyen and Joshua M. Pearce, "Incorporating Shading Losses in Solar Photovoltaic Potential Assessment at the Municipal Scale” Solar Energy 86(5), pp. 1245-1260 (2012). DOI: http://dx.doi.org/10.1016/j.solener.2012.01.017

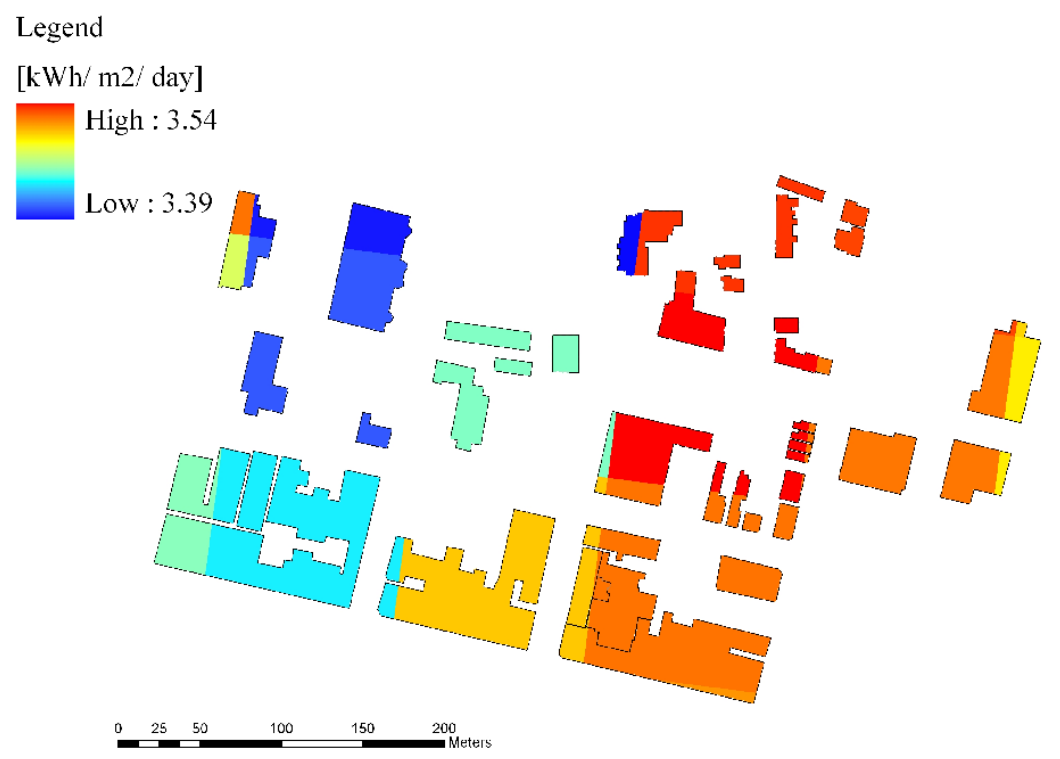

Figure 5. Annual daily irradiation on roof tops of site for a simulation at $90 \mathrm{~m}$ resolution.

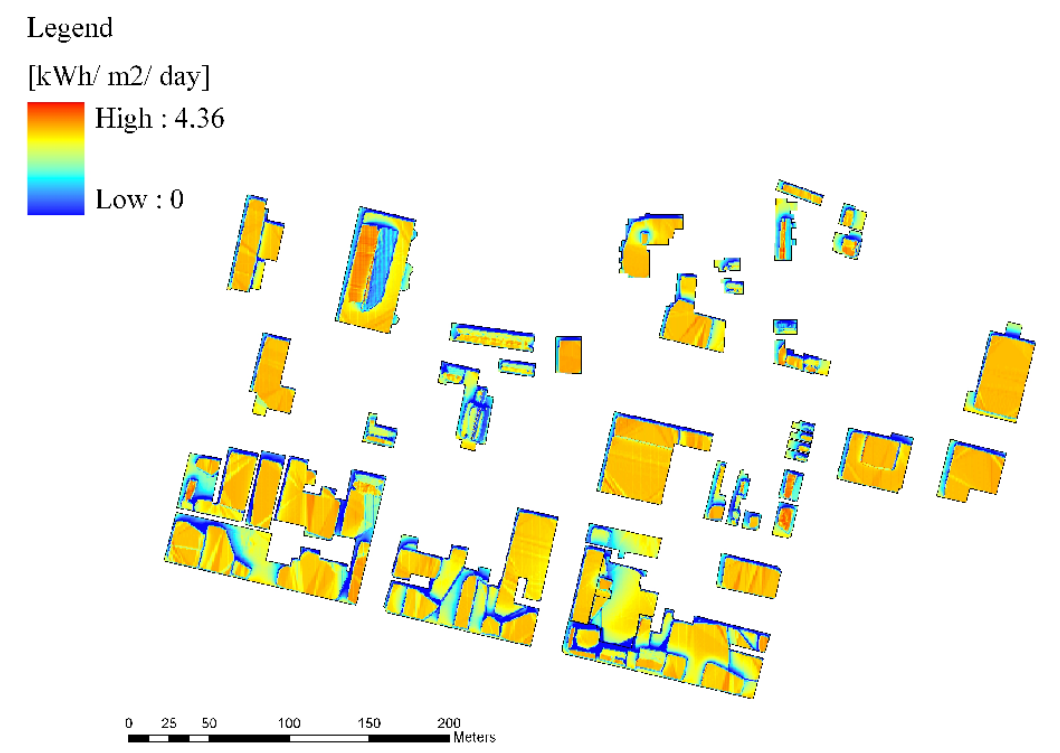

Figure 6. Annual daily irradiation on roof tops of site for a simulation at $0.55 \mathrm{~m}$ resolution. 
Published as: Ha T. Nguyen and Joshua M. Pearce, "Incorporating Shading Losses in Solar Photovoltaic Potential Assessment at the Municipal Scale” Solar Energy 86(5), pp. 1245-1260 (2012). DOI: http://dx.doi.org/10.1016/j.solener.2012.01.017

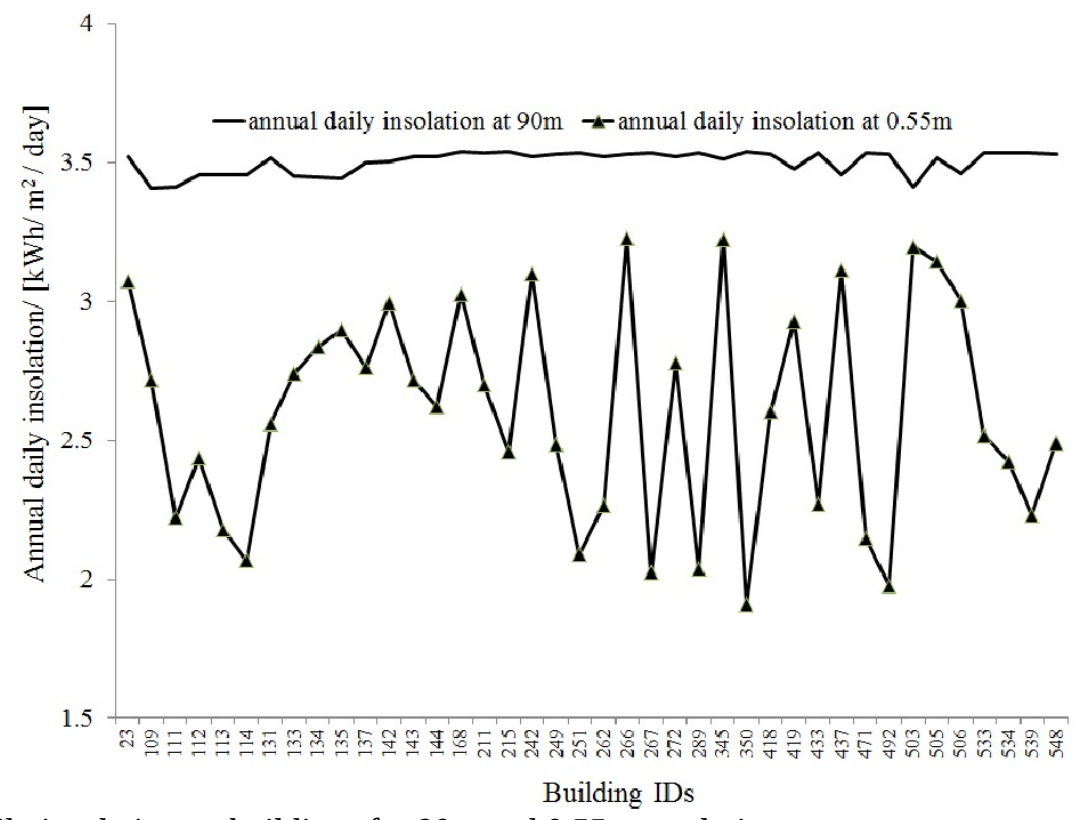

Figure 7. Annual daily insolation on buildings for $90 \mathrm{~m}$ and $0.55 \mathrm{~m}$ resolutions.

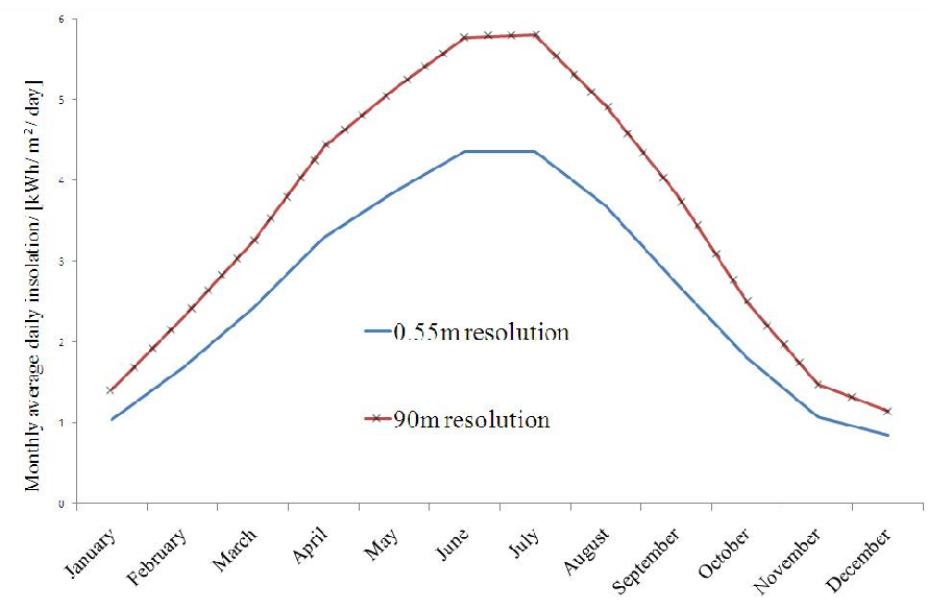

Figure 8 . Monthly average daily insolation for $90 \mathrm{~m}$ and $0.55 \mathrm{~m}$ resolutions.

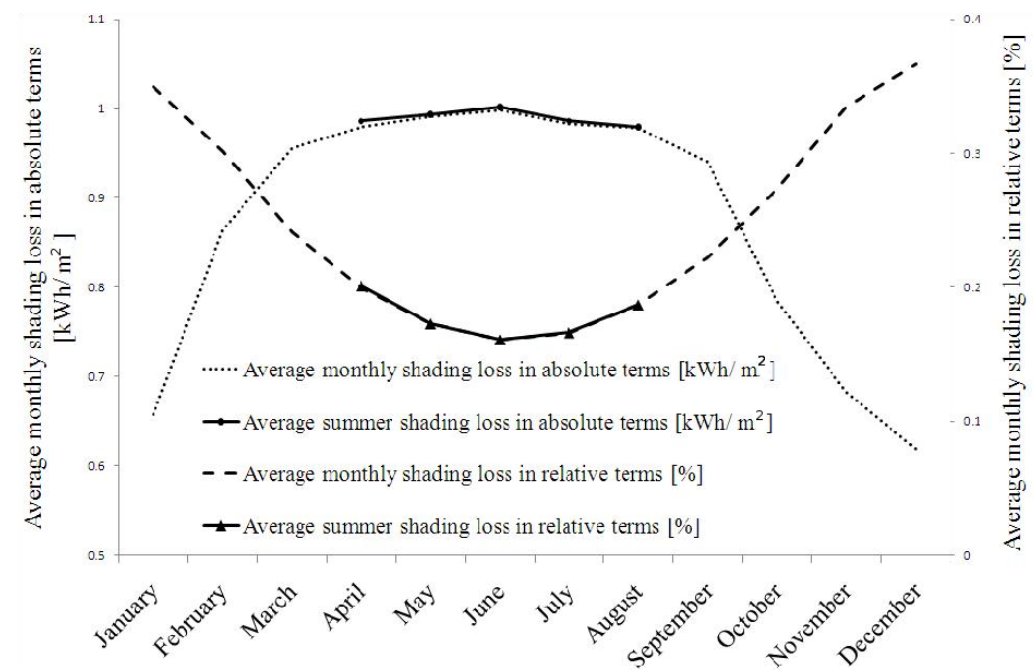

Figure 9. Monthly irradiation losses in absolute and relative terms. 
Published as: Ha T. Nguyen and Joshua M. Pearce, "Incorporating Shading Losses in Solar Photovoltaic Potential Assessment at the Municipal Scale” Solar Energy 86(5), pp. 1245-1260 (2012). DOI: http://dx.doi.org/10.1016/j.solener.2012.01.017

\section{Legend}

$\square$ roof faces due northeast through northwest

roof faces due southwest through southeast

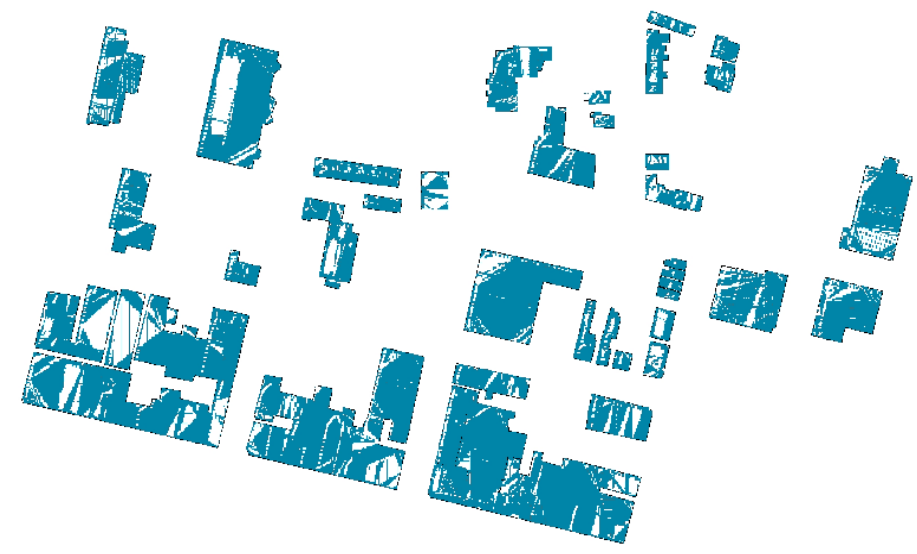

Figure 10. Roof sections of suitable aspects in selected site.

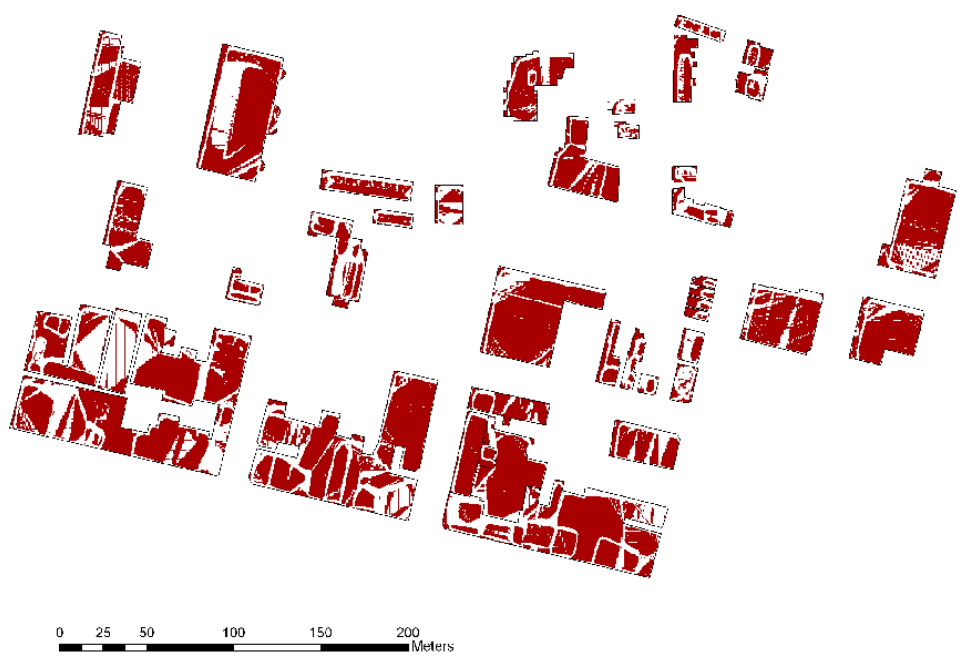

Figure 11. Roof sections most suitable for installing PV systems in selected site. 